\title{
MEMORY MODULATION
}

\author{
Benno Roozendaal ${ }^{1}$ and James L. McGaugh ${ }^{2}$
}

${ }^{1}$ Department of Neuroscience, Section Anatomy, University Medical Center Groningen, University of Groningen, 9713 AV Groningen, the Netherlands ${ }^{2}$ Center for the Neurobiology of Learning and Memory and Department of Neurobiology and Behavior, University of California, Irvine, CA 92697-3800, USA

\begin{abstract}
Our memories are not all created equally strong: Some experiences are well remembered while others are remembered poorly, if at all. Research on memory modulation investigates the neurobiological processes and systems that contribute to such differences in the strength of our memories. Extensive evidence from both animal and human research indicates that emotionally significant experiences activate hormonal and brain systems that regulate the consolidation of newly acquired memories. These effects are integrated through noradrenergic activation of the basolateral amygdala which regulates memory consolidation via interactions with many other brain regions involved in consolidating memories of recent experiences. Modulatory systems not only influence neurobiological processes underlying the consolidation of new information, but also affect other mnemonic processes, including memory extinction, memory recall and working memory. In contrast to their enhancing effects on consolidation, adrenal stress hormones impair memory retrieval and working memory. Such effects, as with memory consolidation, require noradrenergic activation of the basolateral amygdala and interactions with other brain regions.
\end{abstract}

\section{Keywords}

epinephrine; norepinephrine; basolateral amygdala; acetylcholine; hippocampus; neocortex; caudate nucleus; retrograde amnesia; corticosterone; glucocorticoids; stress hormones; inhibitory avoidance; emotional arousal; memory extinction; memory consolidation; memory retrieval; working

Over a century ago, William James (1890) asked a critical question that continues to guide current memory research: "Of some [experiences] no memory survives the instance of their passage. Of others, it is confined to a few moments, hours or days. Others, again, leave vestiges that are indestructible, and by means of which they may be recalled as long as life endures. How can we explain these differences? (James, 1890 p 643)." Understanding the neurobiological processes and systems that contribute to such differences in the strength of our memories is the focus of research on memory modulation. Modulatory systems not only

Correspondence: Benno Roozendaal, Department of Neuroscience, Section Anatomy, University Medical Center Groningen, University of Groningen, Antonius Deusinglaan 1, 9713 AV Groningen, The Netherlands. Phone: (+31) 50 363 2452; Fax: (+31) 50 363 2461; b.roozendaal@med.umcg.nl.

Publisher's Disclaimer: The following manuscript is the final accepted manuscript. It has not been subjected to the final copyediting, fact-checking, and proofreading required for formal publication. It is not the definitive, publisher-authenticated version. The American Psychological Association and its Council of Editors disclaim any responsibility or liabilities for errors or omissions of this manuscript version, any version derived from this manuscript by NIH, or other third parties. The published version is available at www.apa.org/pubs/journals/bne 
influence neurobiological processes underlying the consolidation of new information, but also affect other mnemonic processes, including memory extinction, retrieval and working memory.

\section{Enhancement of Memory Consolidation}

Memory modulation research began with studies of the effects of drugs on learning. In the first published study of the effect of a drug on learning, Lashley (1917) reported that low doses of strychnine administered to rats prior to training on a maze enhanced their performance. Subsequent studies reported additional evidence that strychnine and other stimulant drugs administered prior to training enhanced performance on tasks that employed different kinds of motivation and different behavioral responses (McGaugh \& Roozendaal, 2009).

Drug studies that use pretraining administration must confront the critical issue of determining the basis (or bases) of the enhanced performance (McGaugh, 1989). Learning and memory are, of course, inferred from experience-induced changes in behavior. Thus, the distinction between learning and performance, originally proposed by Tolman (1932), is essential for understanding modulatory influences on learning and memory. Findings of experimentally induced retrograde amnesia (Duncan, 1949; McGaugh 1966; McGaugh \& Herz, 1972) suggested an alternative approach to investigating drug effects on learning and memory: If memories are susceptible to disruption by treatments applied shortly after learning (Müller \& Pilzecker, 1900), they should also be susceptible to enhancement by posttraining treatments administered after learning. Posttraining treatments thus provide a means of distinguishing drug effects on memory from other effects on performance, as the subjects can be drug-free during both acquisition and retention testing (McGaugh, 1973; McGaugh \& Petrinovich, 1965).

There is now extensive evidence that administration of CNS stimulants enhance memory when administered shortly after training (McGaugh \& Roozendaal, 2009). Such findings provide strong evidence that the treatments enhance memory by modulating memory consolidation processes (McGaugh, 2000).

\section{Adrenal Stress Hormone Modulation}

The finding that posttraining drug treatments can enhance memory consolidation suggested the possibility that endogenous processes activated by experiences may serve to regulate the consolidation of the experiences (McGaugh, 1983; McGaugh \& Gold, 1989). Hormones of the adrenal medulla (epinephrine) and adrenal cortex (cortisol; corticosterone in rodents) are released during and immediately after emotionally arousing stimulation of the kinds typically used in training tasks (Aguilar-Valles et al., 2005; Joëls \& Baram, 2009; McCarty \& Gold, 1981; McGaugh \& Gold, 1989). There is now extensive evidence that these hormones modulate memory consolidation (Oitzl \& de Kloet, 1992; McGaugh \& Roozendaal, 2002; Roozendaal, 2000; Roozendaal, Nguyen, Power \& McGaugh, 1996b; Roozendaal, McEwen \& Chattarji, 2009a).

\section{Epinephrine}

Gold and van Buskirk $(1975,1978)$ were the first to report that, in adrenally intact rats, systemic injections of the adrenomedullary hormone epinephrine enhance long-term retention of inhibitory avoidance when administered shortly after training (Figure 1). Comparable effects were obtained in subsequent experiments using many different types of training tasks commonly used in experiments with rats and mice (Costa-Miserachs, PortellCortes, Aldavert-Vera, Torras-Garcia \& Morgado-Bernal, 1994; Introini-Collison \& 
McGaugh, 1986; Izquierdo \& Dias, 1985; Liang, Julier \& McGaugh, 1986; Sternberg et al., 1985).

As epinephrine does not readily cross the blood-brain barrier (Weil-Malherbe, Axelrod \& Tomchick, 1959), its effects on memory consolidation appear to be initiated, at least in part, by activation of $\beta$-adrenoceptors located in the periphery. This conclusion is supported by the finding that sotalol, a $\beta$-adrenoceptor antagonist that does not readily enter the brain, blocks the enhancing effects of peripherally administered epinephrine on memory (IntroiniCollison, Saghafi, Novack \& McGaugh, 1992). Epinephrine effects are most likely mediated by activation of $\beta$-adrenoceptors located on vagal afferents that project to the nucleus of the solitary tract (NTS) in the brain stem (Schreurs, Seelig \& Schulman, 1986) that sends noradrenergic projections directly and indirectly, via the locus coeruleus, to forebrain regions (Ricardo \& Koh, 1978; Williams \& Clayton, 2001; Williams \& Jensen, 1991; Williams \& McGaugh, 1993). Thus, the NTS appears to be an interface between peripheral adrenergic activation and brain processes regulating memory consolidation. However, posttraining peripheral administration of $\beta$-adrenoceptor agonists that enter the brain, including dipivefrin and clenbuterol, also enhance memory. Such enhancement is blocked by the $\beta$-adrenoceptor antagonist propranolol that readily enters the brain, but not by the peripherally acting antagonist sotalol (Introini-Collison et al., 1992).

The finding that posttraining peripheral administration of glucose produces dose- and timedependent effects on memory comparable to those produced by epinephrine (Gold, 1986) suggests that epinephrine may influence memory consolidation, in part, by enhancing glycogenolysis in the liver (Gold, 1995; Messier \& White, 1984, 1987). Doses of epinephrine and glucose that are optimal for enhancing retention induce comparable levels of plasma glucose (Hall \& Gold, 1986). Glucose readily enters the brain and, thus, can directly influence brain glucoreceptors (Oomura, Nakano, Lenard, Nishino \& Aou, 1988). The finding that memory is also influenced by peripherally administered fructose, a sugar that has little influence on the brain, suggests that this sugar as well as glucose may act, at least in part, at peripheral sites in influencing memory (Messier \& White, 1987). In support of this view, Talley and colleagues (Talley, Clayborn, Jewel, McCarthy \& Gold, 2002) reported that vagotomy blocks the memory-enhancing effects of peripherally administered L-glucose, an enantiomer of glucose that does not cross the blood-brain barrier.

\section{Glucocorticoids}

Adrenocortical hormones released by emotionally arousing stimulation are also involved in modulating memory consolidation (Bohus, 1994; de Kloet, 1991; Joëls, Pu, Wiegert, Oitzl \& Krugers, 2006; Lupien \& McEwen, 1997; McEwen \& Sapolsky, 1995; Roozendaal, 2000; Sandi \& Pinelo-Nava, 2007). Posttraining injections of glucocorticoids produce dose- and time-dependent enhancement of memory (Cottrell \& Nakajima, 1977; Okuda, Roozendaal \& McGaugh, 2004; Roozendaal \& McGaugh, 1996a; Sandi \& Rose, 1994; Zorawski \& Killcross, 2002). Glucocorticoids are highly lipophylic and, thus, readily enter the brain and bind directly to mineralocorticoid receptors (MRs) and glucocorticoid receptors (GRs) (de Kloet, 1991; McEwen, Weiss \& Schwartz, 1968;). MRs have a high affinity for the natural steroids corticosterone and aldosterone and are mostly saturated during basal corticosterone levels whereas GRs become occupied by higher levels of corticosterone (Reul \& de Kloet, 1985; Reul, de Kloet, van Sluys, Rijnberk \& Rothuizen, 1990; Sutanto \& de Kloet, 1987). The memory-modulating effects of glucocorticoids appear to involve the selective activation of the low-affinity GRs (Lupien \& McEwen, 1997; Oitzl \& de Kloet, 1992; Roozendaal, Portillo-Marquez \& McGaugh, 1996b) as blockade of GRs, but not MRs, shortly before or immediately after training impairs long-term memory. Glucocorticoids are known to act through intracellular and intranuclear receptors and can affect gene transcription by direct binding of receptor homodimers to DNA (Beato, Herrlich \& Schutz, 1995; Datson, van der 
Perk, de Kloet \& Vreugdenhil, 2001) or via protein-protein interactions with other transcription factors such as Jun or Fos (Heck et al., 1994). However, as discussed below, glucocorticoids may also act more rapidly by interacting with membrane receptors and/or potentiating the efficacy of the norepinephrine signal cascade via an interaction with Gprotein-mediated actions (Barsegyan, Mackenzie, Kurose, McGaugh \& Roozendaal, 2010; Dallman, 2005; Joëls, Fernandez \& Roozendaal, 2011; Karst, Berger, Erdmann, Schutz \& Joëls, 2010; Roozendaal, Quirarte \& McGaugh, 2002a; Tasker, Di \& Malcher-Lopes, 2006).

\section{Adrenergic-Glucocorticoid Interactions}

Evidence from several kinds of studies indicates that catecholamines and glucocorticoids released from the adrenal glands interact in influencing neural plasticity and memory consolidation (Joëls et al., 2011; Pu, Krugers \& Joëls, 2009; Roozendaal et al., 2006b). Glucocorticoids alter the sensitivity of epinephrine in influencing memory consolidation in adrenalectomized rats (Borrell, de Kloet, Versteeg \& Bohus, 1983; Borrell, de Kloet \& Bohus, 1984). Meytrapone, a corticosterone-synthesis inhibitor that reduces the elevation of circulating corticosterone induced by aversive stimulation, attenuates the memory-enhancing effects of epinephrine (Roozendaal, Carmi \& McGaugh, 1996a). Thus, the synergistic actions of epinephrine and corticosterone may be essential in mediating stress effects on memory enhancement.

The studies cited above used emotionally arousing training, such as inhibitory avoidance, that induces the activation of both corticosterone and epinephrine. To determine whether adrenergic activation induced by emotional arousal is essential in enabling corticosterone effects on memory consolidation more recent studies used an object recognition task (Okuda et al., 2004). Rats were given either extensive habituation to an apparatus, or no prior habituation, and were then allowed to explore objects in the apparatus. Placing rats in a novel testing apparatus evokes novelty-induced arousal and prior habituation of rats to the apparatus reduces the arousal (de Boer, Koopmans, Slangen \& van der Gugten, 1990). Corticosterone administered immediately posttraining to non-habituated rats enhanced their 24-hour memory of the objects. In contrast, in habituated rats posttraining corticosterone did not enhance retention (Okuda et al., 2004), suggesting that training-associated emotional arousal may be essential in enabling glucocorticoid effects on memory consolidation.

Adrenergic activation appears to be a critical component of emotional arousal in enabling glucocorticoid effects on memory consolidation. As is shown in Figure 2, the $\beta$ adrenoceptor antagonist propranolol co-administered with the corticosterone immediately after object recognition training blocked the corticosterone-induced memory enhancement (Roozendaal, Okuda, van der Zee \& McGaugh, 2006a). Additionally, in habituated rats, corticosterone administered together with the noradrenergic stimulant yohimbine (an $\alpha_{2}{ }^{-}$ adrenoceptor antagonist) after object recognition training induced dose-dependent enhancement of memory (Roozendaal et al., 2006a). These findings strongly suggest that adrenergic activation is essential in enabling glucocorticoid enhancement of memory consolidation.

\section{Other Neuromodulatory Systems}

Drugs affecting many other neuromodulatory and transmitter systems also influence memory consolidation (McGaugh, 1989; McGaugh \& Gold, 1989). The memory enhancement induced by stimulant drugs known to act via GABA (picrotoxin, bicuculline) and catecholamines (amphetamine, clenbuterol) is also induced by opiate receptor antagonists (Introini \& Baratti, 1984; Messing et al., 1979) and muscarinic cholinergic receptor agonists (Baratti, Introini \& Huygens, 1984; Flood, Landry \& Jarvik, 1981; Introini-Collison \& McGaugh, 1988; Power, Vazdarjanova \& McGaugh, 2003a; Stratton \& 
Petrinovich, 1963). Drugs and hormones affecting several other systems also enhance memory consolidation: Corticotropin-releasing factor (CRF) (Roozendaal, Brunson, Holloway, McGaugh \& Baram, 2002b), adrenocorticotropin (Gold \& van Buskirk, 1976), vasopressin (de Wied, 1984), oxytocin (Bohus, 1980), substance P (Huston \& Staubli, 1981; Schlesinger et al., 1986), histamine (da Silva, Bonini, Bevilaqua, Izquierdo \& Cammarota, 2006; Passani et al., 2001), cholecystokinin (Flood, Smith \& Morley, 1987), endocannabinoids (Campolongo et al., 2009b) and the fat-induced satiety factor oleoylethanolamide (OEA) (Campolongo et al., 2009a).

As is discussed below, many neuromodulatory systems affect memory consolidation via interactions with noradrenergic and muscarinic cholinergic systems within the basolateral amygdala (BLA). The initial research examining such interactions investigated the effects of peripherally administered drugs and hormones (McGaugh \& Cahill, 1997). Extensive evidence indicates that opiate and GABAergic influences on memory consolidation are mediated via adrenergic influences. The finding that the $\beta$-adrenoceptor antagonist propranolol blocks the memory-enhancing effects of the opiate receptor antagonist naloxone (Izquierdo \& Graudenz, 1980) is consistent with evidence that opiates regulate the release of norepinephrine in the brain (Arbilla \& Langer, 1978; Nakamura, Tepper, Young, Ling \& Groves, 1982). Further, the $\beta$-adrenoceptor agonist clenbuterol blocks the memory impairment induced by the GABAergic agonist muscimol (Introini-Collison, Castellano \& McGaugh, 1994). Such findings are consistent with the hypothesis that opioids and GABA impair memory by decreasing norepinephrine release in the brain (Hatfield, Spanis \& McGaugh, 1999; Quirarte, Galvez, Roozendaal \& McGaugh, 1998).

There is also extensive evidence that muscarinic cholinergic activation is essential for norepinephrine-induced memory enhancement. As systemic injections of the muscarinic cholinergic receptor antagonist atropine attenuate the memory-enhancing effects of the $\beta$ adrenoceptor agonist clenbuterol as well as that of epinephrine (Introini-Collison \& Baratti, 1992; Introini-Collison \& McGaugh, 1988), cholinergic influences on memory consolidation appear to act at a site or sites downstream from adrenergic activation.

\section{Involvement of the Amygdala}

\section{Noradrenergic Influences in the Basolateral Amygdala}

Findings of experiments by Kesner and Ellis (Ellis \& Kesner, 1981; Kesner \& Ellis, 1983) and Gallagher and colleagues (Gallagher, Kapp, Pascoe \& Rapp,1981) were the first to suggest that neuromodulatory systems in the amygdala are involved in influencing memory consolidation. $\beta$-Adrenoceptor antagonists infused into the amygdala posttraining impaired memory and concurrent infusion of norepinephrine blocked the memory impairment (Gallagher et al., 1981). Other early findings indicated that, as is found with systemic administration, posttraining intra-amygdala infusions of opioid peptidergic agonists and antagonists impaired and enhanced memory, respectively (Izquierdo \& Graudenz, 1980; Messing et al., 1979). More recent findings indicate that the basolateral amygdala (BLA) is selectively involved in such memory-modulatory influences: The adjacent central nucleus does not appear to play a significant role (Campolongo et al., 2009b; Da Cunha, Roozendaal, Vazdarjanova \& McGaugh, 1999; McGaugh, Ferry, Vazdarjanova \& Roozendaal, 2000; Parent \& McGaugh, 1994; Roozendaal \& McGaugh, 1996a, 1997a; Tomaz, Dickinson-Anson \& McGaugh, 1992). Thus, the effects of relatively large intraamygdala drug infusion volumes typically used in most early studies as well as many recent studies are likely due selectively to influences on BLA activity. Moreover, findings indicating that posttraining intra-amygdala infusions of drugs influence memory tested 24 hours or longer after the training, but do not affect memory tested within a few hours after training, provide strong evidence that the treatments selectively affect the consolidation of 
long-term memory (Barros et al., 2002; Bianchin, Mello e Souza, Medina \& Izquierdo, 1999; Schafe \& LeDoux, 2000).

Other early findings also suggested that the amygdala may be a critical site mediating adrenergic influences on memory consolidation. Adrenal demedullation or posttraining administration of epinephrine alters the memory-modulating effects of electrical stimulation of the amygdala (Liang et al., 1985) and lesions of either the amygdala or the stria terminalis, an important amygdala input-output pathway, block epinephrine effects on memory consolidation (Cahill \& McGaugh, 1991; Liang \& McGaugh, 1983). Early studies also reported evidence that epinephrine induces the release of norepinephrine in the brain (Gold \& van Buskirk, 1978). The finding that posttraining intra-amygdala infusions of the $\beta$ adrenoceptor antagonist propranolol block epinephrine effects on memory consolidation (Liang et al., 1986) provided the first evidence suggesting that epinephrine effects on memory are mediated specifically by noradrenergic activation within the amygdala. In support of this implication, many subsequent studies found that posttraining infusions of norepinephrine or the $\beta$-adrenoceptor agonist clenbuterol into the amygdala (or selectively into the BLA) enhance memory consolidation (Bianchin et al., 1999; Ferry \& McGaugh, 1999; Hatfield \& McGaugh, 1999; Huff, Wright-Hardesty, Higgins, Matus-Amat \& Rudy, 2005; Introini-Collison, Miyazaki \& McGaugh, 2003; Introini-Collison, Dalmaz \& McGuagh, 1996; Izquierdo et al., 1992; LaLumiere, Buen \& McGaugh, 2003; LaLumiere, Nawar \& McGaugh, 2005; Liang et al., 1986; Liang, McGaugh \& Yao, 1990; Liang, Chen \& Huang, 1995; Roozendaal, Castello, Vedana, Barsegyan \& McGaugh, 2008b). Furthermore, posttraining intra-amygdala infusions of $\beta$-adrenoceptor antagonists impair retention when administered alone and block the memory-enhancing effects of norepinephrine co-administered (Liang et al., 1986; Liang et al., 1995; Roozendaal et al., 2008b; Salinas \& McGaugh, 1995).

In addition to $\beta$-adrenoceptor influences, $\alpha$-adrenoceptor activation in the BLA also modulates memory consolidation. Intra-BLA infusions of the $\alpha_{1}$-adrenoceptor antagonist prazosin impair inhibitory avoidance memory whereas infusions of the non-selective $\alpha$ adrenoceptor agonist phenylephrine, administered together with yohimbine (an $\alpha_{2^{-}}$ adrenoceptor antagonist), enhance retention (Ferry, Roozendaal \& McGaugh, 1999a). Additionally, posttraining infusions of the selective $\alpha_{2}$-adrenoceptor antagonist idazoxan also enhance memory consolidation and the selective $\alpha_{2}$-adrenoceptor agonist UK 14,304 impairs memory (Ferry \& McGaugh, 2008). The $\alpha_{1}$-adrenoceptor-induced memory enhancement most likely involves an interaction with $\beta$-adrenoceptors, as posttraining intraBLA infusions of the $\beta$-adrenoceptor antagonist atenolol block the memory enhancement produced by activation of $\alpha_{1}$-adrenoceptors. Evidence that posttraining intra-amygdala infusions of the synthetic cAMP analog 8-bromo-cAMP enhance retention (Liang et al., $1995)$ is consistent with the hypothesis that activation of $\beta$-adrenoceptors modulates memory via a direct coupling to adenylate cyclase. Thus, the finding that intra-BLA infusions of the $\alpha_{1}$-adrenoceptor antagonist prazosin do not prevent the memory enhancement induced by concurrently infused 8-bromo-cAMP suggests that the memory-enhancing effects of $\alpha_{1}$ adrenoceptor activation are mediated by an interaction with $\beta$-adrenoceptors upstream from cAMP, probably at the G-protein level (Ferry, Roozendaal \& McGaugh, 1999b).

Noradrenergic activity within the BLA is also involved in mediating GABAergic and opioid peptidergic influences on memory consolidation (Roozendaal, 2007). Intra-BLA infusions of the GABAergic receptor antagonists bicuculline and picrotoxin enhance memory consolidation whereas GABAergic receptor agonists impair memory (e.g. Bianchin et al., 1999; Brioni, Nagahara \& McGaugh, 1989; Huff et al., 2005; Izquierdo et al., 1992; Wilensky, Schafe \& LeDoux, 2000). Similarly, posttraining infusions of the opioid peptidergic antagonist naloxone enhance memory and opioid peptidergic agonists impair 
memory (Introini-Collison, Arai \& McGaugh, 1989; McGaugh, Introini-Collison \& Nagahara, 1988). $\beta$-Adrenoceptor antagonists infused into the amygdala block the memoryenhancing effects of bicuculline or naloxone infused concurrently (Introini-Collison et al., 1989; McGaugh et al., 1988, 1990). Raggozino and Gold (1994) reported that posttraining intra-amygdala infusions of glucose block the memory impairment induced by the opiate drug morphine. However, such glucose infusions do not attenuate the memory impairment induced by propranolol (Lennartz, Hellems, Mook \& Gold, 1996; McNay \& Gold, 1998). Thus, glucose effects do not appear to act either via adrenergic activation within the amygdala or at sites downstream of adrenergic activation within the amygdala.

Noradrenergic activation within the BLA is also involved in the memory-modulatory effects of many other treatments. Intra-BLA infusions of $\beta$-adrenoceptor antagonists block the memory enhancement induced by oleoylethanolamide (OEA) (Campolongo et al., 2009a) as well as CRF (Roozendaal, Schelling \& McGaugh, 2008a) and orphanin FQ/nociceptin (OFQ/N) (Roozendaal, Lengvilas, McGaugh, Civelli \& Reinscheid, 2007). Posttraining intra-BLA infusions of CRF enhance memory (Liang \& Lee, 1988) and a CRF receptor antagonist impairs memory (Roozendaal et al., 2002b). In contrast, posttraining intra-BLA infusions of $\mathrm{OFQ} / \mathrm{N}$ impair retention and an $\mathrm{OFQ} / \mathrm{N}$ receptor antagonist enhances retention (Roozendaal et al., 2007). The $\beta$-adrenoceptor antagonist atenolol infused into the BLA blocks the memory-enhancing effect of both $\mathrm{CRF}$ and the $\mathrm{OFQ} / \mathrm{N}$ receptor antagonist, whereas it potentiates the memory-impairing effect of $\mathrm{OFQ} / \mathrm{N}$ administered concurrently (Roozendaal et al., 2007, 2008a).

Other studies have implicated the BLA in the memory-modulatory effects of bombesin (gastrin-releasing peptide). Posttraining intra-BLA infusions of the bombesin receptor antagonist RC-3095 impair memory of inhibitory avoidance (Roesler et al., 2004), whereas temporary inactivation of the BLA blocks the memory-modulatory effects of systemically administered bombesin or its antagonist (Rashidy-Pour \& Razvani, 1998; Roesler et al., 2004). Furthermore, the finding that bombesin infused into the NTS also modulates memory consolidation (Williams \& McGaugh, 1994) and that inactivation of the NTS blocks the effects of peripherally administered bombesin (Rashidy-Pour \& Razvani, 1998) suggests that noradrenergic activity may be essential in mediating the effects of bombesin on memory consolidation

The extensive evidence that adrenoceptor activation within the amygdala modulates memory consolidation suggests that: 1) Emotionally arousing learning experiences should induce the release of norepinephrine within the amygdala and 2) Drugs and hormones that enhance memory consolidation should increase the release of norepinephrine. As is shown in Table 1, findings of studies using in vivo microdialysis and HPLC to measure on-going changes in norepinephrine levels in the amygdala strongly support these implications. Footshock stimulation comparable to that used for inhibitory avoidance training, the task used in many studies discussed above, significantly increases amygdala norepinephrine release (Galvez, Mesches \& McGaugh, 1996; Quirarte et al., 1998). Moreover, drugs and hormones that enhance memory consolidation potentiate footshock-induced increases in norepinephrine levels in the amygdala and drugs that impair consolidation decrease amygdala norepinephrine levels (Hatfield et al. 1999; Kawahara, Hesselink, van Scharrenburg \& Westerink, 2004; Quirarte et al., 1998; Williams, Men, Clayton \& Gold, 1998;). Further, stimulation of the vagus nerve or the NTS increases norepinephrine levels in the amygdala and enhances memory consolidation (Clayton \& Williams, 2000, Hassert, Miyashita \& Williams, 2004). McIntyre et al. (McIntyre, Hatfield \& McGaugh, 2002) found that norepinephrine levels in the amygdala increased significantly after inhibitory avoidance training. Additionally, and importantly, the retention performance of individual animals 
tested the following day correlated highly with levels of amygdala norepinephrine induced by the training (Figure 3).

Experiments investigating the role of amygdala norepinephrine in modulating memory consolidiation have generally used arousing training conditions that induce the release of high levels of norepinephrine in the amygdala. However, recent findings indicate that posttraining noradrenergic activation of the BLA enhances memory of a low-arousing training experience that otherwise would not induce strong memory (Roozendaal et al., 2008b). Rats received intra-BLA infusions of norepinephrine after training in an object recognition task. Prior studies (Okuda et al., 2004) indicated that brief (3 min) exposure to two identical objects would not produce significant 24-hour memory. Importantly, rats given posttraining intra-BLA infusions of norepinephrine after such brief training had enhanced memory on a 24-hour test. Thus, these findings indicate that in the absence of high arousal, noradrenergic activation of the BLA is sufficient to enhance memory consolidation. Rats given longer training exposure (10 min) displayed memory of the objects on the 24 hour test and post-training intra-BLA infusions of propranolol impaired this memory.

\section{Glucocorticoid Influences in the Basolateral Amygdala}

There is extensive evidence that glucocorticoids also affect memory consolidation through influences involving the BLA. The effects of glucocorticoids on memory for inhibitory avoidance training are highly similar to those of epinephrine. Lesions of the BLA or stria terminalis block the memory-enhancing effects of posttraining systemic injections of the synthetic glucocorticoid dexamethasone (Roozendaal \& McGaugh, 1996a, 1996b).

Furthermore, either systemic or intra-BLA infusions of glucocorticoids modulate memory consolidation (Roozendaal \& McGaugh, 1996a, 1997a) and, as with effects of epinephrine, such modulation requires noradrenergic activation within the amygdala. A $\beta$-adrenoceptor antagonist infused into the BLA postraining blocks the memory-enhancing effects of systemic injections of dexamethasone and corticosterone as well as the effects of the GR agonist RU 28362 infused into the BLA concurrently (Roozendaal et al., 2002a, 2006a, 2006b; Quirarte, Roozendaal \& McGaugh, 1997). Moreover, electrophysiologial evidence indicates that glucocorticoids increase the excitability of BLA neurons (Duvarci \& Paré, 2007).

As discussed above, studies investigating the effects of glucocorticoids administered systemically after object recognition training found that, in naïve (i.e., emotionally aroused) rats, propranolol blocked the corticosterone-induced memory enhancement and that in habituated (i.e., less emotionally aroused) rats corticosterone enhanced memory only when norepinephrine release was stimulated by yohimbine (Roozendaal et al., 2006a). A subsequent experiment (Roozendaal et al., 2006a) found that, in naive rats, intra-BLA infusions of a $\beta$-adrenoceptor antagonist blocked the enhancing effects of systemically administered corticosterone on object recognition memory. Further, in habituated rats, corticosterone activated BLA neurons, as assessed by phosphorylated cAMP responseelement binding (pCREB) immunoreactivity levels, only in animals also given yohimbine. These findings provide strong evidence that the BLA is a critical locus of the synergistic actions of glucocorticoids and emotional arousal-induced noradrenergic activation in influencing memory consolidation.

Findings of studies investigating the mechanism of glucocorticoid interactions with the noradrenergic system suggest that activation of GRs in the BLA may facilitate memory consolidation by potentiating the norepinephrine-induced signaling cascade through an interaction with G-protein-mediated effects. The enhancement of memory for inhibitory avoidance training induced by posttraining intra-BLA infusions of the GR agonist RU 28362 is blocked by concurrent infusion of Rp-cAMPS, a drug that inhibits protein kinase A 
activity and thus blocks the norepinephrine signaling cascade (Roozendaal et al., 2002a). Moreover, intra-BLA infusions of the GR antagonist RU 38486 attenuate the memoryenhancing effects of the $\beta$-adrenoceptor agonist clenbuterol infused concurrently such that a much higher dose of clenbuterol (100 ng vs $1 \mathrm{ng}$ ) is required to induce memory enhancement (Roozendaal et al., 2002a).

As was found with epinephrine, glucocorticoid effects on memory consolidation also appear to involve brain stem nuclei, including the NTS, that send noradrenergic projections to the BLA. A GR antagonist infused into the NTS attenuates the memory-enhancing effects of systemically administered dexamethasone (Roozendaal, Williams \& McGaugh, 1999a). Moreover, the finding that posttraining infusions of RU 28362 into the NTS enhance inhibitory avoidance retention and that intra-BLA infusions of a $\beta$-adrenoceptor antagonist block the enhancement (Roozendaal et al., 1999a) provides additional evidence that the NTS influence on memory consolidation involves noradrenergic activation of the BLA (Clayton \& Williams, 2000; Miyashita \& Williams 2002; Williams et al., 1998; Williams, Men \& Clayton, 2000). The findings of a recent in vivo microdialysis experiment suggest that glucocorticoids facilitate the training-induced release of norepinephrine in the amygdala (McReynolds et al., 2010). Corticosterone administered immediately after inhibitory avoidance training increased amygdala norepinephrine levels whereas corticosterone administered to non-aroused control animals did not affect norepinephrine levels in the amygdala. Interestingly, as norepinephrine levels in the amygdala were elevated within 15 min after the corticosterone administration, these effects are compatible with rapid nongenomic effect of glucocorticoids. Other recent studies suggest that such rapid effects of glucocorticoids on the release of norepinephrine in the BLA might depend on endocannabinoid signaling (Campolongo et al., 2009b; Hill \& McEwen, 2009).

\section{Cholinergic influences in the Basolateral Amygdala}

There is extensive evidence that posttraining intra-amygdala infusions of muscarinic cholinergic receptor agonists and antagonists enhance and impair, respectively, memory for many kinds of training, including inhibitory avoidance, Pavlovian fear conditioning, conditioned place preference and change in reward magnitude (Introini-Collison et al., 1996; LaLumiere, Nguyen \& McGaugh, 2004; Passani et al., 2001; Power \& McGaugh, 2002; Power et al., 2003a; Power, McIntyre, Litmanovich \& McGaugh, 2003b; Salinas, IntroiniCollison, Dalmaz \& McGaugh, 1997; Schroeder \& Packard, 2002; Vazdarjanova \& McGaugh, 1999). Further, lesions of the nucleus basalis, the major source of cholinergic innervation of the BLA, impair inhibitory avoidance retention and posttraining intra-BLA infusions of either oxotremorine or the acetylcholinesterase inhibitor physostigmine attenuate the memory impairment (Power \& McGaugh, 2002).

Cholinergic activation in the BLA appears to act downstream from adrenergic activation in modulating memory consolidation. A $\beta$-adrenoceptor antagonist does not block the memoryenhancing effect of intra-amygdala infusions of oxotremorine. However, a low and otherwise ineffective dose of the muscarinic cholinergic receptor antagonist atropine blocks the memory enhancement induced by intra-amygdala infusions of clenbuterol (Dalmaz, Introini-Collison \& McGaugh, 1993; Salinas et al., 1997). Cholinergic activation within the BLA is critical for enabling glucocorticoid as well as dopamine enhancement of memory consolidation. Atropine infused into the BLA blocks the memory-enhancing effects of RU 28362 or dopamine infused concurrently as well as the effects of systemically administered dexamethasone (LaLumiere et al., 2004; Power, Roozendaal \& McGaugh, 2000).

Conversely, cholinergic activation within the BLA affecting memory also appears to require concurrent interaction with dopamine as dopamine receptor antagonists block the memoryenhancing effects of posttraining intra-BLA infusions of oxotremorine (LaLumiere et al., 2004). 
Figure 4 summarizes some of the neuromodulatory interactions within the BLA involved in regulating memory consolidation.

\section{Involvement of the Amygdala in Modulating Memory Extinction}

Extinction learning, learning that cues that previously predicted aversive or appetitive consequences no longer predict such consequences, is regulated by the same neuromodulatory systems that regulate original learning. An early study found that posttraining peripheral administration of the GABAergic antagonist picrotoxin enhances the extinction of cued fear conditioning (McGaugh et al., 1990). More recent findings indicate that posttraining intra-BLA infusions of the GABAergic antagonist bicuculline as well as norepinephrine enhance extinction of contextual fear conditioning (Berlau \& McGaugh, 2006). Further propranolol, infused into the BLA, blocks bicuculline induced enhancement of memory consolidation. And, the GABAergic agonist muscimol infused into the BLA together with norepinephrine posttraining does not block the enhanced extinction induced by norepinephrine. Thus, these findings provide additional evidence that norepinephrine effects within the BLA act downstream from GABAergic influences (Introini-Collison et al., 1994; McGaugh \& Cahill, 1997).

Intra-BLA infusions of the NMDA partial agonist d-cycloserine administered either pre- or post-extinction also enhance extinction of fear conditioning (Ledgerwood, Richardson \& Cranney, 2003, 2005; Walker, Ressler, Lu \& Davis, 2002). Furthermore, infusions of dcycloserine block the impairing effects of concurrent administration of the GABAergic agonist muscimol on the consolidation of extinction memory (Akirav, 2007).

Dexamethasone administered systemically after extinction training or intra-amygdally prior to extinction enhanced extinction of fear-potentiated startle (Yang, Chao \& Lu, 2006). Other studies have reported that the BLA modulates the extinction of conditioned place preference. Glucose or oxotremorine infused into the BLA immediately after extinction training enhance the extinction of amphetamine-induced place preference (Schroeder \& Packard, 2003; Schroeder \& Packard, 2004).

\section{Amygdala Interactions With Other Brain Regions}

As discussed above, many of the experiments investigating BLA involvement in memory consolidation have used inhibitory avoidance training and testing (Izquierdo et al., 1997; McGaugh \& Izquierdo, 2000; McGaugh, Ferry, Vazdarjanova \& McGaugh, 2000; Parent \& McGaugh, 1994; Wilensky et al., 2000). However, comparable effects of posttraining amygdala treatments have been obtained with many different kinds of training tasks, including contextual fear conditioning (LaLumiere et al., 2003; Sacchetti, Lorenzini, Baldi, Tassoni \& Bucherelli, 1999; Vazdarjanova \& McGaugh, 1999;), cued fear conditioning (Hui et al., 2004; Roozendaal et al., 2006b; Sacchetti et al., 1999; Schafe \& LeDoux, 2000), Ymaze discrimination training (McGaugh et al., 1988), change in reward magnitude (Salinas et al., 1997), conditioned place preference (Hsu, Schroeder \& Packard, 2002; Schroeder \& Packard, 2003, 2004), radial-arm maze appetitive training (Packard \& Chen, 1999), watermaze spatial and cued training (Packard \& Teather, 1998; Packard, Cahill \& McGaugh, 1994), conditioned taste aversion (Miranda, LaLumiere, Buen, Bermudez-Rattoni \& McGaugh, 2003; Miranda, Quirarte, Rodriguez-Garcia, McGaugh \& Roozendaal, 2008), olfactory training (Kilpatrick \& Cahill, 2003), object recognition (Roozendaal et al., 2006a), extinction of contextual fear conditioning (Berlau \& McGaugh, 2006) and extinction of conditioned reward (Schroeder \& Packard, 2003).

As these different training experiences are known to engage different brain systems (Gold, 2004; Izquierdo et al., 1997; McGaugh, 2002; Packard \& Cahill, 2001; Packard \& Knowlton, 2002; Quillfeldt et al., 1996; Zanatta et al., 1996), the BLA-induced modulation 
no doubt involves influences on processing occurring in these different brain regions. This implication is supported by the finding that training known to involve the amygdala (e.g., Pavlovian fear conditioning) induces the expression of several transcriptionally regulated genes implicated in synaptic plasticity in many brain areas, including the hippocampus, striatum and cortex, as well as the amygdala (Ressler, Paschall, Zhou \& Davis, 2002). These effects appear to be involved in memory consolidation and not due to non-specific effects of stress or arousal, as they were found only when the stimuli used in the training induced learning.

\section{Interactions with the Caudate Nucleus, Hippocampus and Nucleus Accumbens}

The amygdala projects directly to the caudate nucleus (via the stria terminalis) and both directly and indirectly to the hippocampus (Petrovich, Canteras \& Swanson, 2001; Pitkänen, 2000). The evidence that stria terminalis lesions block the memory-enhancing effects of oxotremorine infused posttraining into the caudate nucleus indicates that efferents from the amygdala influence memory processing involving the caudate nucleus (Packard, IntroiniCollison \& McGaugh, 1996). Considerable evidence indicates that the caudate nucleus and hippocampus are involved in different aspects of memory (e.g. McDonald \& White, 1993; Packard \& Cahill, 2001; Packard \& McGaugh, 1992, 1996). Packard and colleagues (Packard \& Teather, 1998; Packard et al., 1994) found that amphetamine infused posttraining into the caudate nucleus selectively enhanced memory of visually cued watermaze training whereas infusions administered into the dorsal hippocampus selectively enhanced memory of spatial training. In contrast, amphetamine infused into the amygdala posttraining enhanced both cued and place memory. Inactivation of the hippocampus (with lidocaine) prior to testing blocked retention of the spatial training whereas inactivation of the caudate nucleus blocked retention of the visually cued training. In contrast, inactivation of the amygdala prior to retention testing did not block memory of either kind of training. Thus, the amygdala modulates the consolidation of both caudate nucleus-dependent and hippocampus-dependent memory but is not a critical locus of memory for either type of training.

In fear conditioning tasks, including inhibitory avoidance, that are typically used in memory modulation studies the rats learn that footshock occurs in a specific context. Such information can be learned if rats are first exposed to the context and then, on a subsequent day, given a brief footshock. As is shown in Figure 5, infusions of oxotremorine administered into the hippocampus after context exposure enhanced the subsequent conditioning but infusions administered after the footshock training were ineffective (Malin $\&$ McGaugh, 2006). In contrast, oxotremorine infused into the rostral anterior cingulate cortex selectively enhanced memory when administered after the footshock. Oxotremorine infused into the BLA enhanced retention when administered after either the context or footshock training. These findings provide additional evidence that amygdala influences on memory consolidation are not restricted to specific kinds of information.

Studies of the effects of posttraining intra-amygdala infusions of a GR agonist provide additional evidence of BLA-hippocampus interactions in memory consolidation. As is shown in Figure 6, unilateral posttraining intra-hippocampal infusions of the specific GR agonist RU 28362 enhance rats' retention of inhibitory avoidance training and the enhancement is blocked selectively by ipsilateral infusions of a $\beta$-adrenoceptor antagonist into the BLA. Lesions of the BLA, stria terminalis or nucleus accumbens also block the enhancement induced by GR activation in the hippocampus (Roozendaal \& McGaugh, 1997b; Roozendaal et al., 1999b; Roozendaal, de Quervain, Ferry, Setlow \& McGaugh, 2001). The BLA projects to the nucleus accumbens primarily via the stria terminalis (Kelley, Domesick \& Nauta, 1982; Wright, Beijer \& Groenewegen, 1996). The possible involvement of the BLA-stria terminalis-nucleus accumbens pathway in modulating memory 
consolidation was suggested by the finding that lesions of the nucleus accumbens, like lesions of the BLA, block the memory-enhancing effects of systemically administered dexamethasone (Roozendaal \& McGaugh, 1996a; Setlow, Roozendaal \& McGaugh, 2000). Furthermore, the finding that unilateral lesions of the BLA combined with contralateral (unilateral) lesions of the nucleus accumbens also blocked the dexamethasone effect strongly indicates that these two structures interact via the stria terminalis in influencing memory consolidation (Setlow et al., 2000). The finding (LaLumiere et al., 2005) that infusions of a dopamine receptor antagonist selectively into the nucleus accumbens shell block the memory enhancement induced by intra-BLA infusions of dopamine provides further evidence of BLA-nucleus accumbens interactions in modulating memory consolidation. Conversely, a dopamine receptor antagonist infused into the BLA blocks the memory enhancement induced by dopamine infused into the nucleus accumbens shell posttraining (Figure 7). As the hippocampus is known to project to the nucleus accumbens, that region may be a critical locus of converging BLA and hippocampal modulatory influences on memory consolidation (Mulder, Hodenpijl \& Lopes da Silva,, 1998). The finding that inactivation of the nucleus accumbens with infusions of bupivacaine prior to training blocks the acquisition of contextual fear conditioning provides evidence consistent with this hypothesis (Haralambous \& Westbrook, 1999).

Noradrenergic stimulation of the BLA that enhances memory consolidation also increases dorsal hippocampal levels of activity-regulated cytoskeletal protein (Arc) (McIntyre et al., 2005), an immediate-early gene implicated in hippocampal synaptic plasticity and memory consolidation processes (Guzowski et al., 2000). Additionally, inactivation of the BLA with infusions of lidocaine impairs memory consolidation and decreases Arc protein levels in the dorsal hippocampus (McIntyre et al., 2005). The finding that intra-BLA infusions of muscimol attenuate the increase in Arc mRNA induced by contextual fear conditioning provides further evidence that the BLA modulates memory consolidation via regulation of Arc expression in the hippocampus (Huff et al., 2006).

Studies of BLA influences on hippocampal neuroplasticity provide additional important evidence of amygdala-hippocampal interactions (Abe, 2001). Electrical stimulation of the BLA enhances the induction of long-term potentiation (LTP) in the dentate gyrus of the hippocampus (Akirav \& Richter-Levin, 1999; Almaguer-Melian, Martinez-Marti, Frey \& Bergado, 2003; Frey, Bergado-Rosado, Seidenbecher, Pape \& Frey, 2001; Ikegaya, Saito \& Abe, 1995b), but appear to block LTP in the CA1 region of the hippocampus (Vouimba \& Richter-Levin, 2005). Also, selective lesions of the BLA or infusions of a $\beta$-adrenoceptor antagonist into the BLA block the induction of LTP in the dentate gyrus (Ikegaya, Saito \& Abe, 1994, 1995a; Ikegaya, Saito, Abe \& Nakanishi, 1997). Norepinephrine and corticosterone both influence the effects of BLA stimulation on dentate gyrus LTP (Akirav \& Richter-Levin, 2002; Vouimba, Yaniv \& Richter-Levin, 2007). Recent findings indicate that electrical stimulation of the BLA also enhances LTP at cortical synapses onto striatal neurons (Popescu, Saghyan \& Paré, 2007) and that coherent gamma oscillations couple the BLA and striatum during learning (Popescu, Popa \& Paré, 2009). Such findings fit well with the evidence that amygdala activation enhances consolidation of striatal-dependent memory (Packard \& Teather, 1998; Packard et al., 1994).

Pavlovian fear conditioning induces an increase in synchronization of theta-frequency activity in the lateral amygdala and CA1 region of the hippocampus (Pape, Narayanan, Smid, Stork \& Seidenbecher, 2005). Such findings strongly suggest that activation of an amygdala-hippocampus circuit is involved in fear-based learning. Studies of synchronized oscillatory activity occurring within the BLA suggest that such activity may facilitate temporal lobe as well as neocortical processes involved in consolidating explicit or declarative memory (Paré, 2003; Pelletier \& Paré, 2004). The firing of cells in the BLA of 
cats is increased greatly by a single footshock and the increased firing lasts for at least two hours (Pelletier, Likhtik, Filali \& Paré, 2005). Such increased firing may serve to modulate memory processing in efferent brain regions, including the entorhinal cortex and hippocampus (McGaugh, 2005; Paré, Collins \& Pelletier, 2002; Pelletier \& Paré, 2004; Tully \& Bolshakov, 2010).

\section{Basolateral Amygdala-Cortical Interactions}

Findings of several studies indicate that the BLA also modulates cortical functioning involved in memory consolidation. Neurons within the BLA project directly to the entorhinal cortex (Paré \& Gaudreau, 1996; Paré, Dong \& Gaudreau, 1995; Petrovich et al., 2001; Pikkarainen, Ronko, Savander, Insausti \& Pitkanen, 1999). Memory enhancement induced by posttraining drug infusions administered into the entorhinal cortex (Izquierdo \& Medina, 1997) requires a functioning BLA, as lesions of the BLA prevent the memory enhancement induced by 8-bromo-cAMP infused posttraining into the entorhinal cortex (Roesler, Roozendaal \& McGaugh, 2002). BLA lesions or blocking of $\beta$-adrenoceptors in the BLA also prevent the memory-enhancing effects of 8-bromo-cAMP infused posttraining into the insular cortex (Miranda \& McGaugh, 2004) and of oxotremorine infused into the rostral anterior cingulate cortex (Malin, Ibrahim, Tu \& McGaugh, 2007). Additionally, cortical functioning is essential for BLA memory-modulatory effects. Lesions of the rostral anterior cingulate cortex block the memory-enhancing effects of oxotremorine infused posttraining into the BLA (Malin et al., 2007). However, the rostral anterior cingulate cortex and the BLA serve quite different functions in memory. As discussed above, the anterior cingulate cortex appears to play a somewhat selective role in memory for nociceptive information whereas the BLA is not dedicated to the selective modulation of any specific kind of information (Malin \& McGaugh, 2006; McGaugh, 2002; Packard et al., 1994).

There is aloso evidence indicating that the BLA and the medial prefrontal cortex interact in regulating memory consolidation. Inactivation of the medial prefrontal cortex with the AMPA receptor antagonist CNQX impairs consolidation of inhibitory avoidance memory (Liang, Hu \& Chang, 1996). In contrast, activation of noradrenergic and dopaminergic mechanisms in the medial prefrontal cortex enhances consolidation of inhibitory avoidance and trace fear conditioning (Liang, 2001; Runyan \& Dash, 2004). A GR agonist infused into the medial prefrontal cortex induces similar memory enhancement (Roozendaal et al., 2009b). However, lesions of the BLA block the GR agonist-induced memory enhancement. Furthermore, consistent with the evidence of reciprocal inhibitory influences between both brain regions (McDonald, 1991; Rosenkranz \& Grace, 2002; Perez-Jaranay \& Vives, 1991), infusions of RU 28362 into the medial prefrontal cortex after inhibitory avoidance training increases BLA activity, as assessed with phosphorylation of extracellular signal-regulated kinase type 1 and 2 (Erk1/2), a member of the mitogen-activated protein kinase family (Roozendaal et al., 2009b). Further, blockade of this increase in phosphorylated Erk1/2 levels in the BLA with the MEK inhibitor PD98059 blocks the memory enhancement induced by medial prefrontal cortex GR agonist infusions. Interestingly, infusions of a GR agonist into the BLA induce a similar increase in phosphorylated Erk1/2 activity in the medial prefrontal cortex, suggesting mutual interactions between both brain regions in regulating memory consolidation.

The BLA also influences cortical functioning, at least in part, via its projection through the stria terminalis (Price, 1981) to the nucleus basalis, which provides cholinergic activation of the cortex. Several findings suggest that the nucleus basalis-cortical projections may be essential for learning-induced cortical plasticity (Miasnikov, McLin \& Weinberger, 2001; Miasnikov, Chen \& Weinberger, 2006; Weinberger, 2003). Stimulation of the BLA activates the cortex, as indicated by EEG desynchronization, and potentiates nucleus basalis influences on cortical activation. Moreover, inactivation of the nucleus basalis with 
lidocaine blocks the BLA effects on cortical activation (Dringenberg \& Vanderwolf, 1996; Dringenberg, Saber \& Cahill, 2001). Thus, the BLA may influence cortical functioning in memory consolidation, at least in part, through its effects on the nucleus basalis and consequent cholinergic activation of the cortex. In support of this suggestion, Power et al. (Power, Thal \& McGaugh, 2002) reported that selective lesions of cortical nucleus basalis corticopetal cholinergic projections induced by 192-IgG saporin blocked the dose-dependent enhancement of inhibitory avoidance induced by posttraining intra-BLA infusions of norepinephrine (Figure 8). Thus, it is clear that cortical cholinergic activity is required for BLA influences on memory consolidation.

BLA activation also directly influences the consolidation of cortical plasticity. It is well established that stimuli that acquire importance gain increased representation in the cortex. Auditory training shifts the tuning of neurons in the primary auditory cortex to the frequency of the conditioning stimulus and increases in the significance of the stimulus importance increase the area of representational gain (Weinberger, 2004). Moreover, and importantly, repeated pairing of a tone with BLA stimulation induces specific tuning shifts of auditory receptive fields toward that of the CS (Chavez, McGaugh \& Weinberger, 2009). This evidence that BLA activation induces highly specific and enduring learning-related modifications of stimulus representations in the cortex provides additional evidence that the BLA influences on memory involve interactions with other brain regions, including the cortex.

Figure 9 summarizes the interaction of the BLA with other systems in regulating memory consolidation.

\section{Amygdala Activity and Modulation of Human Memory Consolidation}

The findings of human studies on the effects of emotional arousal, stress hormones and amygdala activation on memory are consistent with those of animal studies discussed above (Buchanan \& Adolphs, 2004; Cahill, 2000; Cahill \& McGaugh, 1998, 2000; de Quervain, Aerni, Schelling \& Roozendaal, 2009; Dolan, 2000; LaBar \& Cabeza, 2006; Smeets, Otgaar, Candel \& Wolf, 2008). Cortisol administered to subjects prior to presentations of words or pictures enhance subsequent recall (Abercrombie, Kalin, Thurow, Rosenkranz \& Davidson, 2003; Abercrombie, Speck \& Monticelli, 2006; Buchanan \& Lovallo, 2001; Kuhlmann \& Wolf, 2006; Van Stegeren, Roozendaal, Kindt, Wolf \& Joëls, 2010). Amphetamine administered to human subjects, either before or after they learn lists of words, also enhances long-term memory (Soetens, D’Hooge \& Hueting, 1993; Soetens, Casaer, D'Hooge \& Hueting, 1995). Administration of propranolol to subjects prior to their viewing an emotionally arousing slide presentation blocks the enhancing effects of emotional arousal on long-term memory (Cahill, Prins, Weber \& McGaugh, 1994; Hurlemann et al., 2008; Van Stegeren, 2008). Propranolol also blocks the memory enhancement produced by stressreleased epinephrine (Nielson \& Jensen, 1994). Further, epinephrine or cold pressor stress (that stimulates the release of adrenal stress hormones) administered to subjects after a learning session enhances the subjects' memory of the acquired information (Cahill \& Alkire, 2003; Cahill, Gorski \& Le, 2003; Smeets et al., 2008). Similar effects are produced by administration of the $\alpha_{2}$-adrenoceptor antagonist yohimbine, which stimulates norepinephrine release (O'Carroll, Drysdale, Cahill, Shajahan \& Ebmeier, 1999; Southwick et al., 2002). Additionially, individuals who have a deletion variant of $A D R A 2 B$, the gene encoding the $\alpha_{2 b}$-adrenoceptor, have enhanced emotional memory (de Quervain et al., 2007a). Other studies indicated synergistic actions between the glucocorticoid and noradrenergic systems in human memory enhancement (Hurlemann et al., 2008; Van Stegeren et al., 2010). Further, studies in which participants were classified as 'highresponders' and 'low-responders' in terms of their cortisol elevations and emotional arousal 
in response to stress suggest that stress affects memory only if participants show a robust increase in both cortisol and arousal (Abercrombie et al., 2006; Schwabe, Bohringer, Chatterjee \& Schachinger, 2008).

There is extensive evidence that amygdala activation is involved in enabling the enhanced memory induced by emotional arousal. Memory for emotionally arousing material is not enhanced in human subjects with selective bilateral lesions of the amygdala (Adolphs, Cahill, Schul \& Babinsky, 1997; Cahill, Babinsky, Markowitsch \& McGaugh, 1995). Findings of studies using positron emission tomography (PET) and functional magnetic resonance imaging (fMRI) brain imaging provide additional evidence that the influence of emotional arousal on human memory involves amygdala activation. In the first study of the relationship between amygdala activity during encoding and subsequent memory Cahill et al. (1996) found that amygdala activity assessed by PET imaging conducted while subjects viewed emotionally arousing films correlated highly $(+0.93)$ with the subjects' recall of the films assessed in a surprise memory test three weeks later. Importantly, the degree of emotional arousal rather than the valence of the emotionally arousing material is critical in influencing memory. In subsequent studies using PET imaging Hamann et al. (Hamann, Eli, Grafton \& Kilts, 1999; Hamann, Eli, Hoffman \& Kilts, 2002) reported that amygdala activity induced by viewing either pleasant or unpleasant slides correlated highly with memory for the slides assessed one month later. Studies using fMRI have obtained highly similar findings. Canli et al. (Canli, Zhao, Brewer, Gabrieli \& Cahill, 2000) found that subjects' memory for a series of emotionally arousing scenes tested three weeks after brain scanning correlated highly with amygdala activity induced by viewing the scenes. Furthermore, and importantly, the relationship between amygdala activity during encoding and subsequent memory was greatest for the scenes that the subjects had rated as being the most emotionally intense. Thus, when assessed during encoding, PET imaging of amygdala activity that is assessed over many minutes of arousal as well as event-related fMRI of amygdala activity induced by single items both predict long-term memory of the arousing stimuli (Cahill et al., 1996; Canli et al., 2000).

Human memory studies have provided additional evidence of the importance of noradrenergic activation of the amygdala (Van Stegeren, 2009). $\beta$-Adrenoceptor antagonists (e.g. propranolol) block both the increase in amygdala activity and the enhanced retention induced by emotional stimuli obtained in fMRI studies (Strange \& Dolan, 2004; Van Stegeren et al., 2005). Thus, $\beta$-adrenergic activation of the amygdala appears to be essential for the short-latency modulation induced by brief and mild emotional arousal used in fMRI studies as well as the effects found in human and animal studies with longer intervals of time between learning and stress hormone activation or administration. With both PET and fMRI experiments, activity of the right amygdala is related to enhanced memory in men whereas activity of the left amygdala is correlated with enhanced memory in women (Cahill et al., 2001; Cahill, Uncapher, Kilpatrick, Alkire \& Turner, 2004; Canli et al., 2001).

Understanding the bases of such sex differences may provide further insights into mechanisms of emotional arousal underlying influences on memory consolidation. In this respect it is interesting to note that a recent study reported that epinephrine administration enhanced traumatic memories in male, but not female, patients after cardiac surgery, whereas a $\beta$-adrenoceptor antagonist selectively impaired such memories in female patients (Krauseneck et al., 2010).

Other findings based on an analysis of PET and fMRI scans provide evidence, consistent with that of many animal studies, suggesting that amygdala activation influences memory processing in other brain regions. Activation of the amygdala and hippocampal/ parahippocampal regions is correlated during emotional arousal (Hamann et al., 1999) and such activation is correlated with subsequent retention (Dolcos, LaBar \& Cabeza, 2004; 
Kensinger \& Schacter, 2006; Ritchey, Dolcos \& Cabeza, 2008). Findings of a "path analysis" (structural equation modeling) study (Kilpatrick \& Cahill, 2003) of amygdala activity (based on PET) suggest that emotional arousal increases amygdala influences on activity of the ipsilateral parahippocampal gyrus and ventrolateral prefrontal cortex. Other human studies indicate that $\beta$-adrenoceptor activation increases amygdala-hippocampal interactions in memory consolidation (Strange \& Dolan, 2004) and that a genetic variation of the noradrenergic system increased connectivity between the amygdala and the insula during the encoding of emotional memories (Rasch et al., 2009). Such findings provide additional evidence that amygdala influences on activity of other brain regions are critical in creating lasting memories.

\section{Involvement of the Amygdala in Modulating Memory Retrieval and Working Memory}

Most studies investigating neuromodulatory influences on memory have focused on the processes underlying the consolidation of recent experiences. There is, additionally, considerable evidence that neuromodulatory systems influence memory retrieval and working memory. Consistent with its role in memory consolidation, recent findings indicate that the BLA, via its projections to other brain regions, also plays an important modulatory role in regulating these memory functions.

\section{Memory Retrieval}

Stress exposure or the glucocorticoid corticosterone administered systemically shortly before testing for memory of training on inhibitory avoidance, contextual fear conditioning or water-maze spatial tasks (24 hours earlier) produces temporary impairment of retention performance (Bohus, 1973; Cai, Blundell, Han, Greene \& Powell, 2006; de Quervain, Roozendaal \& McGaugh, 1998; Roozendaal, de Quervain, Schelling \& McGaugh, 2004a; Pakdel \& Rashidy-Pour, 2006; Sajadi, Samaei \& Rashidy-Pour, 2006; Yang et al., 2003). As the same treatments administered shortly before training do not affect either acquisition or retention performance assessed immediately after acquisition, such findings indicate that glucocorticoids impair retention by influencing memory retrieval. These findings are consistent with those indicating that stress exposure or glucocorticoids administered immediately after a learning session also impair retention performance tested 30-60 minutes after the session, i.e. at a time when the memory trace has not yet been consolidated into long-term memory (Diamond, Park, Heman \& Rose, 1999; Okuda et al., 2004; Woodson, Macintosh, Fleshner \& Diamond, 2003). Similarly, as is found with memory consolidation, glucocorticoid effects on memory retrieval require concurrent activation of noradrenergic mechanisms. The $\beta$-adrenoceptor antagonist propranolol administered systemically 30 minutes before inhibitory avoidance retention testing blocks the memory retrieval impairment induced by concurrent injections of corticosterone (Roozendaal et al., 2004a). The finding that stimulation of $\beta_{1}$-adrenoceptors with systemic injections of the selective agonist xamoterol induces memory retrieval impairment comparable to that seen after corticosterone administration (Roozendaal, Hahn, Nathan, de Quervain \& McGaugh, 2004b), suggests that glucocorticoid effects on memory retrieval impairment involve activation of noradrenergic mechanisms.

Peripheral administration of the opioid peptidergic antagonist naloxone or D2 dopamine receptor antagonists also blocks the impairing effect of concurrently administered corticosterone or dexamethasone on memory retrieval (Rashidy-Pour, Sadeghi, Taherain, Vafaei \& Fathollahi, 2004; Pakdel \& Rashidy-Pour, 2006). Memory retrieval is also influenced by systemic administration of drugs affecting several other modulatory systems, including epinephrine, adrenocorticotropin, $\beta$-endorphin, vasopressin, acetylcholine and 
serotonin (e.g., Altman, Stone \& Ogren, 1987; Izquierdo, Barros, Medina \& Izquierdo, 2002; Sato et al., 2004). In investigating drug effects on learning and memory, including memory retrieval, it is critically important to distinguish the effects of the drugs on memory retrieval from those on other processes that may affect the behavior used to assess memory. Not all of the studies cited above adequately controlled for such performance effects.

Many studies have reported evidence that the hippocampus is involved in retrieval of spatial and contextual information (Hirsch, 1974; Squire, Clark \& Knowlton, 2001). Inactivation of the hippocampus with local infusions of the glutamatergic AMPA/kainate receptor antagonist LY326325 or the GABAergic agonist muscimol impairs memory retrieval of water-maze spatial and contextual fear conditioning tasks (Holt \& Maren, 1999; Riedel et al., 1999). As the GR agonist RU 28362 administered into the hippocampus shortly before retention testing also impairs retrieval of spatial memory (Roozendaal, Griffith, Burnaday, de Quervain \& McGaugh, 2003; Roozendaal et al., 2004b), such findings indicate that glucocorticoid-induced memory retrieval impairment of such training depends, in part, on GR activation in the hippocampus. Consistent with the findings of experiments using peripherally administered drugs, a $\beta$-adrenoceptor antagonist infused into the hippocampus prevents the retrieval-impairing effect of a GR agonist administered concurrently (Roozendaal et al., 2004b). Other studies have shown that the effect of novelty stress on memory retrieval is blocked by intrahippocampal infusions of the AMPA receptor antagonist CNQX, the metabotropic glutamate receptor antagonist MCPG, as well as the cAMP blocker Rp-cAMPs (Izquierdo, Barros, Medina \& Izquierdo, 2000). In contrast, infusions of the protein-synthesis inhibitor anisomycin do not block corticosterone effects on memory retrieval (Sajadi et al., 2006), suggesting that stress and corticosterone may influence memory retrieval through a protein synthesis-independent mechanism, a finding consistent with the rapid onset of stress and glucocorticoid effects on memory retrieval.

Retrieval of memory of emotionally arousing information also induces activation of the BLA (Boujabit, Bontempi, Destrade \& Gisquet-Verrier, 2003; Hall, Thomas \& Everitt, 2001). Furthermore, intra-BLA infusions of norepinephrine or CNQX affect retrieval of memory for inhibitory avoidance training (Barros et al., 2001; Liang et al., 1996). In contrast, intra-BLA infusions of a GR agonist do not appear to affect memory retrieval (Roozendaal et al., 2003). However, the BLA interacts with the hippocampus in mediating glucocorticoid effects on memory retrieval. Lesions of the BLA or infusions of a $\beta$ adrenoceptor antagonist into the BLA block the impairing effect of a GR agonist infused into the hippocampus on memory retrieval (Roozendaal et al., 2003, 2004b). These findings are thus consistent with those discussed above concerning memory consolidation (e.g., Roozendaal \& McGaugh, 1997b; Roozendaal et al., 1999b) and indicate that the BLA regulates memory retrieval via interactions with other brain regions.

The findings of studies examining stress hormone effects on memory retrieval in humans are consistent with those of animal experiments and indicate that glucocorticoids impair memory retrieval via an interaction with noradrenergic mechanisms. Stress-level cortisol or cortisone administration to human subjects impairs memory retrieval of emotionally arousing information or during emotionally arousing test conditions (Buchanan \& Adolphs, 2004; Buchanan, Tranel \& Adolphs, 2006; Buss, Wolf, Witt \& Hellhammer, 2004; de Quervain, Roozendaal, Nitsch, McGaugh \& Hock, 2000; Het, Ramlow \& Wolf, 2005; Kuhlmann \& Wolf, 2006; Kuhlmann, Kirschbaum \& Wolf, 2005a; Kuhlmann, Piel \& Wolf, 2005b; Schwabe \& Wolf, 2009; Smeets et al., 2009; Tollenaar, Elzinga, Spinhoven \& Everaerd, 2009; Wolf et al., 2001) and the $\beta$-adrenoceptor antagonist propranolol administered orally blocks the impairing effect of glucocorticoids on memory retrieval (de Quervain, Aerni \& Roozendaal, 2007b; Schwabe et al., 2009). Findings of imaging studies indicate that glucocorticoid effects on memory retrieval in human subjects are also 
mediated, at least in part, by actions in the hippocampus (de Quervain et al., 2003; Oei et al., 2007). However, other findings of human imaging studies indicate that the amygdala is also activated during the retrieval of previously learned emotionally arousing material and indicate that the effect is independent of the valence of the emotional material (Dolan, 2000). Further, findings of human brain imaging studies are consistent with findings of animal studies in indicating that the amygdala and hippocampus interact during the retrieval of emotionally arousing information (Dolcos, LaBar \& Cabeza, 2005; Greenberg et al., 2005; Smith, Stephan, Rugg \& Dolan, 2006).

\section{Working Memory}

Evidence from lesion, pharmacological, imaging and clinical studies indicates that working memory, a dynamic process whereby information is updated continuously, depends on the integrity of the medial prefrontal cortex (Brito, Thomas, Davis \& Gingold, 1982; Fuster, 1991; Lee \& Kesner, 2003; Levy \& Farrow, 2001; Rowe, Toni, Josephs, Frackowiak \& Passingham, 2000; Stern, Sherman, Kirchoff \& Hasselmo, 2001; Taylor, Birnbaum, Ubriani $\&$ Arnsten, 1999). Decrements in prefrontal cortical function are induced by local depletion of norepinephrine and dopamine, suggesting that these monoamines regulate prefrontal cortical function (Brozoski, Brown, Rosvold \& Goldman, 1979; Bubser \& Schmidt, 1990; Cai, Ma, Xu \& Hu, 1993). The importance of endogenous norepinephrine and dopamine stimulation in the medial prefrontal cortex is indicated by studies in which local infusion of either noradrenergic $\alpha_{2}$ (Li, Mao, Wang \& Mei, 1999) or dopaminergic D1 antagonists (Sawaguchi \& Goldman-Rakic, 1991; Seamans, Floresco \& Phillips, 1998) administered into the medial prefrontal cortex impairs performance on working memory tasks. In contrast, activation of $\alpha_{2}$-adrenoceptors with guanfacine improves working memory functions in rats and monkeys. Together, these data suggest that norepinephrine and dopamine are necessary for optimal medial prefrontal cortical function.

Excessive levels of norepinephrine or dopamine, however, impair working memory (Arnsten, 2009). The impairing effects of high doses of norepinephrine are mediated by activation of the $\alpha_{1}$ - and $\beta$-adrenoceptor (Arnsten \& Jentsch, 1997; Arnsten, Mathew, Ubriani, Taylor \& Li, 1999; Birnbaum, Gobeske, Auerbach, Taylor \& Arnsten, 1999; Ramos et al., 2005). In contrast, $\alpha_{2}$-adrenoceptor activation enhances working memory (Taylor et al., 1999). Electrophysiological studies have shown increased medial prefrontal cortical activity in the delay period during which the information needs to be retained (Fuster, 1991). Adrenergic agents that enhance working memory increase this neuronal activity during the delay period, whereas adrenergic drugs that impair working memory decrease such neuronal activity (Li et al., 1999). Dopaminergic D1 receptor agonists influence working memory following an inverted-U shaped dose-response relationship. Too little or too much D1 receptor stimulation impairs prefrontal cortical activity and working memory in mice, rats and monkeys (Cai \& Arnsten, 1997; Li et al., 1999; Lidow, Koh \& Arnsten, 2003; Zahrt, Taylor, Mathew \& Arnsten, 1997).

Working memory deficits are also observed following exposure to stress (Arnsten \& Goldman-Rakic, 1998; Schoofs, Preuss \& Wolf, 2008). Mild uncontrollable stress impairs performance on a delayed alternation task, but does not impair performance on nonmnemonic control tasks that have similar motivational and motor demands (Murphy, Arnsten, Goldman-Rakic \& Roth, 1996). Mild stress, such as noise or exposure to the predator odor TMT, increases norepinephrine and dopamine turnover in the medial prefrontal cortex (Finlay, Zigmond \& Abercrombie, 1995; Morrow, Roth \& Ellsworth, 2000). The medial prefrontal cortex response to stress is blocked by anxiolytic benzodiazepine drugs and mimicked by the anxiogenic benzodiazepine inverse agonist FG7142 (Birnbaum et al., 1999; Murphy et al., 1996; Tam \& Roth, 1985). Also, like stress, glucocorticoid administration impairs working memory. Basal levels of endogenous 
glucocorticoids are required to maintain prefrontal cortical function (Mizoguchi, Ishige, Takeda, Aburada \& Tabita, 2004), but systemic injections of stress doses of corticosterone or intra-medial prefrontal cortical administration of the GR agonist RU 28362 impair working memory, as assessed by delayed alternation performance, in rats (Roozendaal, McReynolds \& McGaugh, 2004c). Additionally, stress-level cortisol treatment impairs prefrontal cortex-dependent inhibitory control of behaviors in squirrel monkeys (Lyons, Lopez, Yang \& Schatzberg, 2000) as well as working memory performance in human subjects (Lupien, Gillin \& Hauger, 1999; Wolf et al., 2001; Young, Sahakian, Robbins \& Cowen, 1999). Glucocorticoids appear to interact with noradrenergic mechanisms in inducing working memory impairment, as systemic administration of the $\beta$-adrenoceptor antagonist propranolol blocks the working memory impairment of corticosterone administered concurrently (Roozendaal et al., 2004c). Furthermore, a $\beta$-adrenoceptor antagonist or cAMP blocker infused into the $\mathrm{mPFC}$ also blocks working memory impairment induced by a GR agonist administered concurrently (Barsegyan et al., 2010).

Glucocorticoid-induced working memory impairment also depends on interactions of the medial prefrontal cortex with the BLA. As discussed above, the BLA both sends projections to and receives projections from the medial prefrontal cortex (McDonald, 1991; Likhtik, Pelletier, Paz \& Paré, 2005; Perez-Jaranay \& Vives, 1991; Rosenkranz \& Grace, 2002). Drug administration into the BLA does not appear to affect working memory (Bianchin et al., 1999; Wan, Pang \& Olton, 1994), but lesions of the BLA block the impairment induced by either systemic administration of corticosterone or infusions of a GR agonist into the medial prefrontal cortex (Roozendaal et al., 2004c) (Figure 10). These findings thus indicate that the BLA interacts with the medial prefrontal cortex in regulating stress hormone effects on working memory.

\section{Interactions Between Emotional Arousal Effects on Different Memory Functions}

The evidence that glucocorticoid hormones, as well as some other neuromodulatory drugs, induce opposite effects on different memory functions raises the intriguing possibility that emotional arousal effects on these different memory functions might be functionally related. It seems possible that a temporary impairment of (task-irrelevant) working memory and memory retrieval functions during emotionally arousing situations might benefit long-term storage of newly acquired information (Kensinger \& Corkin, 2003). Although researchers have just begun to look into this question, we recently reported that local administration of the GR agonist RU 28362 induces medial prefrontal cortex dysfunction and working memory impairment on a delayed alternation task, at least in part, via an activation of the intracellular cAMP/PKA signal transduction pathway (Barsegyan et al., 2010). We further found that such a glucocorticoid-induced disruption of medial prefrontal cortex functioning also induces enhanced consolidation of inhibitory avoidance memory. Importantly, as unilateral infusion of the GR agonist administered into the medial prefrontal cortex enhanced memory consolidation, but did not impair working memory, these findings suggest that glucocorticoid-induced enhancement of memory consolidation does not depend on concurrent impairment of working memory functions per se. Rather, as both memory effects rely on functional interactions between the medial prefrontal cortex and BLA (Roozendaal et al., 2004c; 2009b), glucocorticoid effects on working memory and memory consolidation might be intrinsically linked because of a necessary interaction between the medial prefrontal cortex and BLA. Accordingly, glucocorticoid-induced changes in medial prefrontal cortex functioning might enhance BLA activity, thereby favoring the long-term storage of emotionally arousing experiences (Roozendaal et al., 2009b). Highly relevant in this regard are the findings by Dolcos \& McCarthy (2006) investigating the brain systems mediating cognitive interference by emotional and non-emotional distraction. Training of human participants on a delayed-response working memory task normally evokes robust 
activity during the delay period in typical working memory regions (dorsolateral prefrontal cortex and lateral parietal cortex). However, presentation of novel emotionally salient information (i.e., emotional distracters) during the delay period induced strong activation of the amygdala while simultaneously evoking relative decreased activity in the prefrontal cortex and impairing working memory performance. Although the authors did not investigate long-term memory for the emotional distracters, these findings are consistent with the view that impairment of working memory observed by this pattern of brain activity might be a cost incurred in order to prioritize the processing and consolidation of memory of emotionally salient information.

\section{Concluding Comments}

Research investigating memory modulation evolved from many sources. Key, of course, was Müller and Pilzecker's (1900) Perseveration-Consolidation hypothesis proposed over a century ago. The subsequent findings that treatments that impair brain functioning induce retrograde amnesia (Duncan, 1949; McGaugh \& Herz, 1972) provided critical evidence supporting that hypothesis. Those findings also suggested the possibility that posttraining treatments that stimulate brain activity might enhance memory consolidation. Evidence that posttraining administration of stimulant drugs enhances long-term memory confirmed that implication (Breen \& McGaugh, 1961; McGaugh, 1966, 1973). The early studies of adrenal stress hormone influences on memory consolidation (e.g., Gold \& van Buskirk, 1975, 1976; McGaugh, 1989; McGaugh \& Gold, 1989) provided compelling evidence that peripheral stress hormones released by emotional play an important role. The findings (e.g., Liang et al., 1986) suggesting that stress hormones as well as drugs affect memory by noradrenergic activation of the amygdala (i.e., the BLA) provided strong evidence suggesting that the BLA is an essential part of a memory-modulatory system. This suggestion has now been confirmed by the extensive findings that the BLA interacts with many other brain regions in modulating memory consolidation (McGaugh, 2000, 2002, 2003, 2004). The findings indicating that stress hormones modulate memory retrieval and working memory via noradrenergic influences and the BLA provide yet other chapter to the story of memory modulation (Roozendaal, 2002; Roozendaal et al., 2003, 2004a). Our understanding of memory-modulatory systems is, of course, incomplete. But, in the past several decades, research on memory modulation has made significant progress in understanding how emotional arousal influences the consolidation and retrieval of significant experiences. The recent introduction of genetic and epigenetic methodologies in research on memory modulation (e.g. de Quervain et al., 2007a; Hauer et al., 2011) and the proven clinical usefulness of memory modulation research in understanding and develoving new therapies for affective memory disorders, including post-traumatic stress disorders and phobias (de Quervain et al., 2009; Brunet et al., 2011) will ensure that memory modulation research will remain a central focus of neuroscience for years to come.

\section{Literature Cited}

Abe K. Modulation of hippocampal long-term potentiation by the amygdala: a synaptic mechanism linking emotion and memory. Japanese Journal of Pharmacology. 2001; 86:18-22. [PubMed: 11430468]

Abercrombie HC, Kalin NH, Thurow ME, Rosenkranz MA, Davidson RJ. Cortisol variation in humans affects memory for emotionally laden and neutral information. Behavioral Neuroscience. 2003; 117:506-516.

Abercrombie HC, Speck NS, Monticelli RM. Endogenous cortisol elevations are related to memory facilitation only in individuals who are emotionally aroused. Psychoneuroendocrinology. 2006; 31:187-196. [PubMed: 16225997] 
Adolphs R, Cahill L, Schul R, Babinsky R. Impaired declarative memory for emotional material following bilateral amygdala damage in humans. Learning \& Mememory. 1997; 4:51-54.

Aguilar-Valles A, Sanchez E, de Gortari P, Balderas I, Ramirez-Amaya V, Bermudez-Rattoni F, Joseph-Bravo P. Analysis of the stress response in rats trained in the water-maze: differential expression of corticotropin-releasing hormone, CRH-R1, glucocorticoid receptors and brain-derived neurotrophic factor in limbic regions. Neuroendocrinology. 2005; 82:306-319. [PubMed: 16721035]

Akirav I. NMDA partial agonist reverses blocking of extinction of aversive memory by GABA(A) agonist in the amygdala. Neuropsychopharmacology. 2007; 32:542-550. [PubMed: 16541088]

Akirav I, Richter-Levin G. Biphasic modulation of hippocampal plasticity by behavioral stress and basolateral amygdala stimulation in the rat. Journal of Neuroscience. 1999; 19:10530-10535. [PubMed: 10575049]

Akirav I, Richter-Levin G. Mechanisms of amygdala modulation of hippocampal plasticity. Journal of Neuroscience. 2002; 22:9912-9921. [PubMed: 12427848]

Almaguer-Melian W, Martinez-Marti L, Frey JU, Bergado JA. The amygdala is part of the behavioural reinforcement system modulating long-term potentiation in rat hippocampus. Neuroscience. 2003; 119:319-322. [PubMed: 12770548]

Altman HJ, Stone WS, Ogren SO. Evidence for a possible functional interaction between serotonergic and cholinergic mechanisms in memory retrieval. Behavioral and Neural Biology. 1987; 48:49-62. [PubMed: 3632552]

Arbilla S, Langer SA. Morphine and beta-endorphin inhibit release of noradrenaline from cerebral cortex but not of dopamine from rat striatum. Nature. 1978; 271:559-561. [PubMed: 622192]

Arnsten AFT. Stress signalling pathways that impair prefrontal cortex structure and function. Nature Reviews Neuroscience. 2009; 10:410-422.

Arnsten AFT, Goldman-Rakic PS. Noise stress impairs prefrontal cortical cognitive function in monkeys: evidence for a hyperdopaminergic mechanism. Archives of General Psychiatry. 1998; 55:362-369. [PubMed: 9554432]

Arnsten AFT, Jentsch JD. The alpha-1 adrenergic agonist, cirazoline, impairs spatial working memory performance in aged monkeys. Pharmacology Biochemistry \& Behavior. 1997; 58:55-59.

Arnsten AFT, Mathew R, Ubriani R, Taylor JR, Li BM. Alpha-1 noradrenergic receptor stimulation impairs prefrontal cortical cognitive function. Biological Psychiatry. 1999; 45:26-31. [PubMed: 9894572]

Baratti CM, Introini IB, Huygens P. Possible interaction between central cholinergic muscarinic and opioid peptidergic systems during memory consolidation in mice. Behavioral and Neural Biology. 1984; 40:155-169. [PubMed: 6732709]

Barros DM, Mello e Souza T, de David T, Choi H, Aguzzoli A, Madche C, Ardenghi P, Medina JH, Izquierdo I. Simultaneous modulation of retrieval by dopaminergic $\mathrm{D}(1)$, beta-noradrenergic serotonergic-1A and cholinergic muscarinic receptors in cortical structures of the rat. Behavioral Brain Research. 2001; 124:1-7.

Barros DM, Pereira P, Medina JH, Izquierdo I. Modulation of working memory and of long- but not short-term memory by cholinergic mechanisms in the basolateral amygdala. Behavioral Pharmacology. 2002; 13:163-167.

Barsegyan A, Mackenzie SM, Kurose BD, McGaugh JL, Roozendaal B. Glucocorticoids in the prefrontal cortex enhance memory consolidation and impair working memory by a common neural mechanism. Proceedings of the National Academy of Sciences of the United States of America. 2010; 107:16655-16660. [PubMed: 20810923]

Beato M, Herrlich P, Schutz G. Steroid hormone receptors: many actors in search of a plot. Cell. 1995; 83:851-857. [PubMed: 8521509]

Berlau DJ, McGaugh JL. Enhancement of extinction memory consolidation: the role of the noradrenergic and GABAergic systems within the basolateral amygdala. Neurobiology of Learning and Memory. 2006; 86:123-132. [PubMed: 16458544]

Bianchin M, Mello e Souza T, Medina JH, Izquierdo I. The amygdala is involved in the modulation of long-term memory, but not in working or short-term memory. Neurobiology of Learning and Memory. 1999; 71:127-131. [PubMed: 10082635] 
Birnbaum S, Gobeske KT, Auerbach J, Taylor JR, Arnsten AFT. A role for norepinephrine in stressinduced cognitive deficits: alpha-1-adrenoceptor mediation in the prefrontal cortex. Biological Psychiatry. 1999; 46:1266-1274. [PubMed: 10560032]

Bohus, B. Pituitary-adrenal influences on avoidance and approach behavior of the rat. In: Zimmerman, E.; Gispen, WH.; Marks, BH.; de Wied, D., editors. Progress in brain research: Drug effects on neuroendocrine regulations. Amsterdam: Elsevier; 1973. p. 407-430.

Bohus B. Vasopressin, oxytocin and memory: effects on consolidation and retrieval processes. Acta Psychiatica Belgica. 1980; 80:714-720.

Bohus, B. Humoral modulation of memory processes: physiological significance of brain and peripheral mechanisms. In: Delacour, J., editor. The memory system of the brain. Vol. 4. New Jersey: World Scientific; 1994. p. 337-364.Advanced series of neuroscience

Boujabit M, Bontempi B, Destrade C, Gisquet-Verrier P. Exposure to a retrieval cue in rats induces changes in regional brain glucose metabolism in the amygdala and other related brain structures. Neurobiology of Learning and Memory. 2003; 79:57-71. [PubMed: 12482680]

Borrell J, de Kloet ER, Bohus B. Corticosterone decreases the efficacy of adrenaline to affect passive avoidance retention of adrenalectomized rats. Life Sciences. 1984; 34:99-104. [PubMed: 6694514]

Borrell J, de Kloet ER, Versteeg DH, Bohus B. Inhibitory avoidance deficit following short-term adrenalectomy in the rat: the role of adrenal catecholamines. Behavioral and Neural Biology. 1983; 39:241-258. [PubMed: 6670974]

Breen RA, McGaugh JL. Facilitation of maze learning with posttrial injections of picrotoxin. Journal of Comparative Physiological Psychology. 1961; 54:498-501.

Brioni JD, Nagahara AH, McGaugh JL. Involvement of the amygdala GABAergic system in the modulation of memory storage. Brain Research. 1989; 487:105-112. [PubMed: 2752279]

Brito GNO, Thomas GJ, Davis BJ, Gingold SI. Prelimbic cortex, mediodorsal thalamus, septum and delayed alternation in rats. Experimental Brain Research. 1982; 46:52-58.

Brozoski T, Brown RM, Rosvold HE, Goldman PS. Cognitive deficit caused by regional depletion of dopamine in prefrontal cortex of rhesus monkey. Science. 1979; 205:929-931. [PubMed: 112679]

Brunet A, Poundja J, Tremblay J, Bui E, Thomas E, Orr SP, Azzoug A, Birmes P, Pitman RK. Trauma reactivation under the influence of propranolol decreases posttraumatic stress symptoms and disorder: 3 open-label trials. Journal of Clinical Psychopharmacology. 2011; 31:547-550. [PubMed: 21720237]

Bubser M, Schmidt W. 6-OHDA lesion of the rat prefrontal cortex increases locomotor activity, impairs acquisition of delayed alternation tasks, but does not affect uninterrupted tasks in the radial maze. Behavioral Brain Research. 1990; 37:157-168.

Buchanan, TW.; Adolphs, R. The neuroanatomy of emotional memory in humans. In: Reisberg, D.; Hertel, P., editors. Memory and emotion. Oxford: Oxford University Press; 2004. p. 42-75.

Buchanan TW, Lovallo WR. Enhanced memory for emotional material following stress-level cortisol treatment in humans. Psychoneuroendocrinology. 2001; 26:307-317. [PubMed: 11166493]

Buchanan TW, Tranel D, Adolphs R. Impaired memory retrieval correlates with individual differences in cortisol response but not autonomic response. Learning \& Memory. 2006; 13:382-387. [PubMed: 16741288]

Buss C, Wolf OT, Witt J, Hellhammer DH. Autobiographic memory impairment following acute cortisol administration. Psychoneuroendocrinology. 2004; 29:1093-1096. [PubMed: 15219661]

Cahill, L. Modulation of long-term memory in humans by emotional arousal: adrenergic activation and the amygdala. In: Aggelton, JP., editor. The amygdala. London: Oxford University Press; 2000. p. 425-446.

Cahill L, Alkire M. Epinephrine enhancement of human memory consolidation: interaction with arousal at encoding. Neurobiology of Learning and Memory. 2003; 79:194-198. [PubMed: 12591227]

Cahill L, Babinsky R, Markowitsch HJ, McGaugh JL. The amygdala and emotional memory. Nature. 1995; 377:295-296. [PubMed: 7566084] 
Cahill L, Gorski L, Le K. Enhanced human memory consolidation with post-learning stress: interaction with the degree of arousal at encoding. Learning \&Memory. 2003; 10:270-274. [PubMed: 12888545]

Cahill L, Haier RJ, Fallon J, Alkire M, Tang C, Keator D, Wu J, McGaugh JL. Amygdala activity at encoding correlated with long-term, free recall of emotional information. Proceedings of the National Academy of Sciences of the United Sstates of America. 1996; 93:8016-8021.

Cahill L, Haier RJ, White NS, Fallon J, Kilpatrick L, Lawrence C, Potkin SG, Alkire MT. Sex-related difference in amygdala activity during emotionally influenced memory storage. Neurobiology of Learning and Memory. 2001; 75:1-9. [PubMed: 11124043]

Cahill L, McGaugh JL. NMDA-induced lesions of the amygdaloid complex block the retention enhancing effect of posttraining epinephrine. Psychobiology. 1991; 19:206-210.

Cahill L, McGaugh JL. Mechanisms of emotional arousal and lasting declarative memory. Trends in Neuroscience. 1998; 21:294-299.

Cahill, L.; McGaugh, JL. Emotional learning. In: Kazdin, AE., editor. Encyclopedia of psychology. Washington DC: American Psychological Association and Oxford University Press; 2000. p. 175-177.

Cahill L, Prins B, Weber M, McGaugh JL. $\beta$-adrenergic activation and memory for emotional events. Nature. 1994; 371:702-704. [PubMed: 7935815]

Cahill L, Uncapher M, Kilpatrick L, Alkire MT, Turner J. Sex-related hemispheric lateralization of amygdala function in emotionally influenced memory: an FMRI investigation. Learning \&Memory. 2004; 11:261-266. [PubMed: 15169855]

Cai JX, Arnsten AFT. Dose-dependent effects of the dopamine D1 receptor agonists A77636 or SKF81297 on spatial working memory in aged monkeys. Journal of Pharmacology and Experimental Therapeutics. 1997; 283:183-189. [PubMed: 9336323]

Cai WH, Blundell J, Han J, Greene RW, Powell CM. Postreactivation glucocorticoids impair recall of established fear memory. Journal of Neuroscience. 2006; 26:9560-9566. [PubMed: 16971540]

Cai JX, Ma Y, Xu L, Hu X. Reserpine impairs spatial working memory performance in monkeys: reversal by the alpha-2 adrenergic agonist, clonidine. Brain Research. 1993; 614:191-196. [PubMed: 8102313]

Campolongo P, Roozendaal B, Trezza V, Cuomo V, Astarita G, McGaugh JL, Piomelli D. The fatinduced satiety factor oleoylethanolamide enhances memory consolidation. Proceedings of the National Academy of Sciences of the United States of America. 2009a; 106:8027-8031. [PubMed: 19416833]

Campolongo P, Roozendaal B, Trezza V, Hauer D, Schelling G, McGaugh JL, Cuomo V. Endocannabinoids in the rat basolateral amygdala enhance memory consolidation and enable glucocorticoid modulation of memory. Proceedings of the National Academy of Sciences of the United States of America. 2009b; 106:4888-4893. [PubMed: 19255436]

Canli T, Zhao Z, Brewer J, Gabrieli JD, Cahill L. Event-related activation in the human amygdala associates with later memory for individual emotional experience. Journal of Neuroscience. 2000; 20:RC99. [PubMed: 11000199]

Canli T, Zhao Z, Desmond JE, Kang E, Gross J, Gabrieli JD. An fMRI study of personality influences on brain reactivity to emotional stimuli. Behavioral Neuroscience. 2001; 115:33-42. [PubMed: $11256451]$

Chavez CM, McGaugh JL, Weinberger NM. The basolateral amygdala modulates specific sensory memory representations in the cerebral cortex. Neurobiology of Learning and Memory. 2009; 91:382-392. [PubMed: 19028592]

Clayton EC, Williams CL. Adrenergic activation of the nucleus tractus solitarius potentiates amygdala norepinephrine release and enhances retention performance in emotionally arousing and spatial tasks. Behavioral Brain Research. 2000; 112:151-158.

Costa-Miserachs D, Portell-Cortes IK, Aldavert-Vera L, Torras-Garcia M, Morgado-Bernal I. Longterm memory facilitation in rats by posttraining epinephrine. Behavioral Neuroscience. 1994; 108:469-474. [PubMed: 7917040]

Cottrell GA, Nakajima S. Effect of corticosteroids in the hippocampus on passive avoidance behavior in the rat. Pharmacology, Biochemistry \&Behavior. 1977; 7:277-280. 
Da Cunha C, Roozendaal B, Vazdarjanova A, McGaugh JL. Microinfusions of flumazenil into the basolateral but not the central nucleus of the amygdala enhance memory consolidation in rats. Neurobiology of Learning and Memory. 1999; 72:1-7. [PubMed: 10371710]

Dallman MF. Fast glucocorticoid actions on brain: back to the future. Frontiers in Neuroendocrinology. 2005; 26:103-108. [PubMed: 16242180]

Dalmaz C, Introini-Collison IB, McGaugh JL. Noradrenergic and cholinergic interactions in the amygdala and the modulation of memory storage. Behavioral Brain Research. 1993; 58:167-174.

daSilva WC, Bonini JS, Bevilaqua LR, Izquierdo I, Cammarota M. Histamine enhances inhibitory avoidance memory consolidation through a $\mathrm{H} 2$ receptor-dependent mechanism. Neurobiology of Learning and Memory. 2006; 86:100-106. [PubMed: 16488163]

Datson NA, van der Perk J, de Kloet ER, Vreugdenhil E. Identification of corticosteroid-responsive genes in rat hippocampus using serial analysis of gene expression. European Journal of Neuroscience. 2001; 14:675-689. [PubMed: 11556892]

de Boer SF, Koopmans SJ, Slangen JL, van der Gugten J. Plasma catecholamine, corticosterone and glucose responses to repeated stress in rats: effect of interstressor interval length. Physiology \&Behavior. 1990; 47:1117-1124. [PubMed: 2395915]

de Kloet ER. Brain corticosteroid receptor balance and homeostatic control. Frontiers in Neuroendocrinology. 1991; 12:95-164.

de Quervain DJF, Aerni A, Roozendaal B. Preventive effect of beta-adrenoceptor blockade on glucocorticoid-induced memory retrieval deficits. American Journal of Psychiatry. 2007b; 164:967-969. [PubMed: 17541058]

de Quervain DJF, Aerni A, Schelling G, Roozendaal B. Glucocorticoids and the regulation of memory in health and disease. Frontiers in Neuroendocrinology. 2009; 30:358-370. [PubMed: 19341764]

de Quervain DJF, Henke K, Aerni A, Treyer V, McGaugh JL, Berthold T, Nitsch RM, Buck A, Roozendaal B, Hock C. Glucocorticoid-induced impairment of declarative memory retrieval is associated with reduced blood flow in the medial temporal lobe. European Journal of Neuroscience. 2003; 17:1296-1302. [PubMed: 12670318]

de Quervain DJF, Kolassa IT, Ertl V, Onyut PL, Neuner F, Elbert T, Papassotiropoulos A. A deletion variant of the alpha2b-adrenoceptor is related to emotional memory in Europeans and Africans. Nature Neuroscience. 2007a; 10:1137-1139.

de Quervain DJF, Roozendaal B, McGaugh JL. Stress and glucocorticoids impair retrieval of longterm spatial memory. Nature. 1998; 394:787-790. [PubMed: 9723618]

de Quervain DJF, Roozendaal B, Nitsch RM, McGaugh JL, Hock C. Acute cortisone administration impairs retrieval of long-term declarative memory in humans. Nature Neuroscience. 2000; 3:313314.

de Wied, D. Neurohypophyseal hormone influences on learning and memory processes. In: Lynch, G.; McGaugh, JL.; Weinberger, NM., editors. Neurobiology of learning and memory. New York: The Guilford Press; 1984. p. 289-312.

Diamond DM, Park CR, Heman KL, Rose GM. Exposing rats to a predator impairs spatial working memory in a radial arm water maze. Hippocampus. 1999; 9:542-552. [PubMed: 10560925]

Dolan, RJ. Functional neuroimaging of the amygdala during emotional processing and learning. In: Aggleton, JP., editor. The amygdala. London: Oxford University Press; 2000. p. 631-654.

Dolcos F, McCarthy GM. Brain systems mediating cognitive interference by emotional distraction. Journal of Neuroscience. 2006; 26:2072-2079. [PubMed: 16481440]

Dolcos F, LaBar KS, Cabeza R. Interaction between the amygdala and the medial temporal lobe memory system predicts better memory for emotional events. Neuron. 2004; 42:855-863. [PubMed: 15182723]

Dolcos F, LaBar KS, Cabeza R. Remembering one year later: role of the amygdala and the medial temporal lobe memory system in retrieving emotional memories. Proceedings of the National Academy of Sciences of the United States of America. 2005; 102:2626-2631. [PubMed: 15703295]

Dringenberg H, Saber AJ, Cahill L. Enhanced frontal cortex activation in rats by convergent amygdaloid and noxious sensory signals. NeuroReport. 2001; 12:1295-1298. 
Dringenberg H, Vanderwolf C. Cholinergic activation of the electrocorticogram: an amygdaloid activating system. Experimental Brain Research. 1996; 108:285-296.

Duncan CP. The retroactive effect of electroshock on learning. Journal of Comparative Physiological Psychology. 1949; 42:32-44.

Duvarci S, Paré D. Glucocorticoids enhance the excitability of principal basolateral amygdala neurons. Journal of Neuroscience. 2007; 27:4482-4491. [PubMed: 17442833]

Ellis ME, Kesner RP. Physostigmine and norepinephrine: effects of injection into the amygdala on taste associations. Physiology \&Behavior. 1981; 27:203-209. [PubMed: 7197788]

Ferry B, McGaugh JL. Clenbuterol administration into the basolateral amygdala post-training enhances retention in an inhibitory avoidance task. Neurobiolog of Learning and Memory. 1999; 72:8-12.

Ferry B, McGaugh JL. Involvement of basolateral amygdala alpha2-adrenoceptors in modulating consolidation of inhibitory avoidance memory. Learning \&Memory. 2008; 15:238-243. [PubMed: 18391184]

Ferry B, Roozendaal B, McGaugh JL. Involvement of alpha ${ }_{1}$-adrenergic receptors in the basolateral amygdala in modulation of memory storage. European Journal of Pharmacology. 1999a; 372:9-16. [PubMed: 10374709]

Ferry B, Roozendaal B, McGaugh JL. Basolateral amygdala noradrenergic influences on memory storage are mediated by an interaction between beta- and alpha 1 -receptors. Journal of Neuroscience. 1999b; 19:5119-5123. [PubMed: 10366644]

Finlay JM, Zigmond MJ, Abercrombie ED. Increased dopamine and norepinephrine release in the medial prefrontal cortex induced by acute and chronic stress: effects of diazepam. Neuroscience. 1995; 64:619-628. [PubMed: 7715775]

Flood JF, Landry DW, Jarvik ME. Cholinergic receptor interactions and their effects on long-term memory processing. Brain Research. 1981; 215:177-185. [PubMed: 7260586]

Flood JF, Smith GE, Morley JE. Modulation of memory processing by cholecystokinin: dependence on the vague nerve. Science. 1987; 236:832-834. [PubMed: 3576201]

Frey S, Bergado-Rosado J, Seidenbecher T, Pape HC, Frey JU. Reinforcement of early long-term potentation (early-LTP) in dentate gyrus by stimulation of the basolateral amygdala: heterosynaptic induction mechanisms of late-LTP. Journal of Neuroscience. 2001; 21:3697-3703. [PubMed: 11331399]

Fuster JM. The prefrontal cortex and its relation to behavior. Progress in Brain Research. 1991; 87:201-211. [PubMed: 1907745]

Gallagher, M.; Kapp, BS.; Pascoe, JP.; Rapp, PR. A neuropharmacology of amygdaloid systems which contribute to learning and memory. In: Ben-Ari, Y., editor. The amygdaloid complex. Amsterdam: Elsevier/North-Holland; 1981. p. 343-354.

Galvez R, Mesches M, McGaugh JL. Norepinephrine release in the amygdala in response to footshock stimulation. Neurobiology of Learning and Memory. 1996; 66:253-257. [PubMed: 8946419]

Gold PE. Glucose modulation of memory storage. Behavioral \&Neural Biology. 1986; 45:342-349. [PubMed: 3718398]

Gold PE. Role of glucose in regulating the brain and cognition. American Journal of Clinical Nutrition. 1995; 61:987S-995S. [PubMed: 7900698]

Gold PE. Coordination of multiple memory systems. Neurobiology of Learning and Memory. 2004; 82:230-242. [PubMed: 15464406]

Gold PE, van Buskirk R. Facilitation of time-dependent memory processes with posttrial epinephrine injections. Behavioral Biology. 1975; 13:145-153. [PubMed: 1122202]

Gold PE, van Buskirk R. Enhancement and impairment of memory processes with post-trial injections of adrenocorticotrophic hormone. Behavioral Biology. 1976; 16:387-400. [PubMed: 183641]

Gold PE, van Buskirk R. Post-training brain norepinephrine concentrations: correlation with retention performance of avoidance training with peripheral epinephrine modulation of memory processing. Behavioral Biology. 1978; 23:509-520. [PubMed: 697696]

Greenberg DL, Rice HJ, Cooper JJ, Cabeza R, Rubin DC, LaBar KS. Co-activation of the amygdala, hippocampus and inferior frontal gyrus during autobiographical memory retrieval. Neuropsychologia. 2005; 43:659-674. [PubMed: 15721179] 
Guzowski JF, Lyford GL, Stevenson GD, Houston FP, McGaugh JL, Worley PF, Barnes CA. Inhibition of activity-dependent arc protein expression in the rat hippocampus impairs the maintenance of long-term potentiation and consolidation of long-term memory. Journal of Neuroscience. 2000; 20:3993-4001. [PubMed: 10818134]

Hall JL, Gold PE. The effects of training, epinephrine, and glucose injections on plasma glucose levels in rats. Behavioral and Neural Biology. 1986; 46:156-167. [PubMed: 3767829]

Hall J, Thomas KL, Everitt BJ. Cellular imaging of zif 268 expression in the hippocampus and amygdala during contextual and cued fear memory retrieval: selective activation of hippocampal CA1 neurons during recall of contextual memory. Journal of Neuroscience. 2001; 21:2186-2193. [PubMed: 11245703]

Hamann SB, Eli TD, Grafton ST, Kilts CD. Amygdala activity related to enhanced memory for pleasant and aversive stimuli. Nature Neuroscience. 1999; 2:289-303.

Hamann SB, Eli TD, Hoffman JM, Kilts CD. Ecstacy and agony: activation of the human amygdala in positive and negative emotions. Psychological Science. 2002; 13:135-141. [PubMed: 11933997]

Haralambous T, Westbrook RF. An infusion of bupivacaine into the nucleus accumbens disrupts the acquisition but not the expression of contextual fear conditioning. Behavioral Neuroscience. 1999; 113:925-940. [PubMed: 10571476]

Hassert DL, Miyashita T, Williams CL. The effects of peripheral vagal nerve stimulation at a memorymodulating intensity on norepinephrine output in the basolateral amygdala. Behavioral Neuroscience. 2004; 118:79-88. [PubMed: 14979784]

Hatfield T, McGaugh JL. Norepinephrine infused into the basolateral amygdala posttraining enhances retention in a spatial water maze task. Neurobiology of Learning and Memory. 1999; 71:232239. [PubMed: 10082642]

Hatfield T, Spanis C, McGaugh JL. Response of amygdalar norepinephrine to footshock and GABAergic drugs using in vivo microdialysis and HPLC. Brain Research. 1999; 835:340-345. [PubMed: 10415392]

Hauer D, Weis F, Papassotiropoulos A, Schmoeckel M, Beiras-Fernandez A, Lieke J, Kaufmann I, Kirchhoff F, Vogeser M, Roozendaal B, Briegel J, de Quervain DJF, Schelling G. Relationship of a common polymorphism of the glucocorticoid receptor gene to traumatic memories and posttraumatic stress disorder in patients after intensive care therapy. Critical Care Medicine. 2011; 39:643-650. [PubMed: 21169818]

Heck S, Kullmann M, Gast A, Ponta H, Rahmsdorf HJ, Herrlich P, Cato AC. A distinct modulating domain in glucocorticoid receptor monomers in the repression of activity of the transcription factor AP-1. The EMBO Journal. 1994; 13:4087-4095. [PubMed: 8076604]

Het S, Ramlow G, Wolf OT. A meta-analytic review of the effects of acute cortisol administration on human memory. Psychoneuroendocrinology. 2005; 30:771-784. [PubMed: 15919583]

Hill MN, McEwen BS. Endocannabinoids: the silent partner of glucocorticoids in the synapse. Proceedings of the National Academy of Sciences of the United States of America. 2009; 106:4579-4580. [PubMed: 19293387]

Hirsch R. The hippocampus and contextual retrieval of information from memory: a theory. Behavioral Biology. 1974; 12:421-444. [PubMed: 4217626]

Holt W, Maren S. Muscimol inactivation of the dorsal hippocampus impairs contextual retrieval of fear memory. Journal of Neuroscience. 1999; 19:9054-9062. [PubMed: 10516322]

Hsu EH, Schroeder JP, Packard MG. The amygdala mediates memory consolidation for an amphetamine conditioned place preference. Behavioral Brain Research. 2002; 129:93-100.

Huff NC, Frank M, Wright-Hardesty K, Sprunger D, Matus-Amat P, Higgins E, Rudy JW. Amygdala regulation of immediate-early gene expression in the hippocampus induced by contextual fear conditioning. Journal of Neuroscience. 2006; 26:1616-1623. [PubMed: 16452685]

Huff NC, Wright-Hardesty KJ, Higgins EA, Matus-Amat P, Rudy JW. Context pre-exposure obscures amygdala modulation of contextual-fear conditioning. Learning \& Memory. 2005; 12:456-460. [PubMed: 16204200]

Hui GK, Figueroa IR, Poytress BS, Roozendaal B, McGaugh JL, Weinberger NM. Memory enhancement of classical fear conditioning by post-training injections of corticosterone in rats. Neurobiology of Learning and Memory. 2004; 81:67-74. [PubMed: 14670360] 
Hurlemann R, Rehme AK, Diessel M, Kukolja J, Maier W, Walter H, Cohen MX. Segregating intraamygdalar responses to dynamic facial emotion with cytoarchitectonic maximum probability maps. Journal of Neuroscience Methods. 2007; 172:13-20. [PubMed: 18486975]

Huston, JP.; Staubli, U. Substance P and its effects on learning and memory. In: Martinez, JL., Jr; Jensen, RA.; Messing, RB.; Rigter, H.; McGaugh, JL., editors. Endogenous peptides and learning and memory processes. New York: Academic Press; 1981. p. 521-540.

Ikegaya Y, Saito H, Abe K. Attenuated hippocampal long-term potentiation in basolateral amygdalalesioned rats. Brain Research. 1994; 656:157-164. [PubMed: 7804830]

Ikegaya Y, Saito H, Abe K. Requirement of basolateral amygdala neuron activity for the induction of long-term potentiation in the dentate gyrus in vivo. Brain Research. 1995a; 671:351-354. [PubMed: 7743229]

Ikegaya Y, Saito H, Abe K. High-frequency stimulation of the basolateral amygdala facilitates the induction of long-term potentiation in the dentate gyrus in vivo. Neuroscience Research. 1995b; 22:203-207. [PubMed: 7566701]

Ikegaya Y, Saito H, Abe K, Nakanishi K. Amygdala beta-noradrenergic influence on hippocampal long-term potentiation in vivo. NeuroReport. 1997; 8:3143-3146. [PubMed: 9331930]

Introini IB, Baratti CM. The impairment of retention induced by beta-endorphin in mice may be mediated by reduction of central cholinergic activity. Behavioral and Neural Biology. 1984; 41:152-163. [PubMed: 6148931]

Introini-Collison IB, Arai Y, McGaugh JL. Stria terminalis lesions attenuate the effects of posttraining oxotremorine and atropine on retention. Psychobiology. 1989; 17:397-401.

Introini-Collison IB, Baratti CM. Memory-modulatory effects of centrally acting noradrenergic drugs: possible involvement of brain cholinergic mechanisms. Behavioral and Neural Biology. 1992; 57:248-255. [PubMed: 1319706]

Introini-Collison IB, Castellano C, McGaugh JL. Interaction of GABAergic and $\beta$-noradrenergic drugs in the regulation of memory storage. Behavioral and Neural Biology. 1994; 61:150-155. [PubMed: 8204080]

Introini-Collison IB, Dalmaz C, McGaugh JL. Amygdala $\beta$-noradrenergic influences on memory storage involve cholinergic activation. Neurobiology of Learning and Memory. 1996; 65:57-64. [PubMed: 8673407]

Introini-Collison IB, McGaugh JL. Epinephrine modulates long-term retention of an aversivelymotivated discrimination task. Behavioral and Neural Biology. 1986; 45:358-365. [PubMed: 3718400]

Introini-Collison IB, McGaugh JL. Modulation of memory by posttraining epinephrine: involvement of cholinergic mechanisms. Psychopharmacology (Berlin). 1988; 94:379-385. [PubMed: 3128815]

Introini-Collison IB, Miyazaki B, McGaugh JL. Involvement of the amygdala in the memoryenhancing effects of clenbuterol. Psychopharmacology (Berlin). 1991; 104:541-544. [PubMed: 1780426]

Introini-Collison IB, Saghafi D, Novack G, McGaugh JL. Memory-enhancing effects of posttraining dipivefrin and epinephrine: involvement of peripheral and central adrenergic receptors. Brain Research. 1992; 572:81-86. [PubMed: 1319277]

Izquierdo LA, Barros DM, Medina JH, Izquierdo I. Novelty enhances retrieval of one-trial avoidance learning in rats 1 or 31 days after training unless the hippocampus is inactivated by different receptor antagonists and enzyme inhibitors. Behavioral Brain Research. 2000; 117:215-220.

Izquierdo LA, Barros DM, Medina JH, Izquierdo I. Stress hormones enhance retrieval of fear conditioning acquired either one day or many months before. Behavioral Pharmacology. 2002; 13:203-213.

Izquierdo I, da Cunha C, Rosat R, Jerusalinsky D, Ferreira MBC, Medina JH. Neurotransmitter receptors involved in posttraining memory processing by the amygdala, medial septum and hippocampus of the rat. Behavioral and Neural Biology. 1992; 58:16-26. [PubMed: 1358054]

Izquierdo I, Dias RD. Influence on memory of posttraining or pre-test injections of ACTH, vasopressin, epinephrine and B-endorphin, and their interaction with naloxone. Psychoneuroendocrinology. 1985; 10:165-172. [PubMed: 2994140] 
Izquierdo I, Graundenz M. Memory facilitation by naloxone is due to release of dopaminergic and Badrenergic systems from tonic inhibition. Psychopharmacology (Berlin). 1980; 67:265-268. [PubMed: 6247739]

Izquierdo I, Medina JH. Memory formation: the sequence of biochemical events in the hippocampus and its connection to activity in other brain structures. Neurobiology of Learning and Memory. 1997; 68:285-316. [PubMed: 9398590]

Izquierdo I, Quillfeldt JA, Zanatta MS, Quevedo J, Schaeffer E, Shmitz PK, Medina JH. Sequential role of hippocampus and amygdala, entorhinal cortex and parietal cortex in formation and retrieval of memory for inhibitory avoidance in rats. European Journal of Neuroscience. 1997; 9:786-793. [PubMed: 9153585]

James, W. Principles of psychology. New York: Henry Holt and Company; 1890.

Joëls M, Baram TZ. The neuro-symphony of stress. Nature Reviews Neuroscience. 2009; 10:459-466.

Joëls M, Fernandez G, Roozendaal B. Stress and emotional memory: a matter of timing. Trends in Cognitive Science. 2011; 15:280-288.

Joëls M, Pu Z, Wiegert O, Oitzl MS, Krugers HJ. Learning under stress: how does it work. Trends in Cognitive Science. 2006; 10:152-158.

Karst H, Berger S, Erdmann G, Schütz G, Joëls M. Metaplasticity of amygdalar responses to the stress hormone corticosterone. Proceedings of the National Academy of Sciences of the United States of America. 2010; 107:14449-14454. [PubMed: 20663957]

Kawahara Y, Hesselink MB, van Scharrenburg G, Westerink BHC. Tonic inhibition by orphanin FQ/ nociceptin of noradrenaline neurotransmission in the amygdala. European Journal of Pharmacology. 2004; 485:197-200. [PubMed: 14757141]

Kensinger EA, Corkin S. Effect of negative emotional content on working memory and long-term memory. Emotion. 2003; 3:378-393. [PubMed: 14674830]

Kensinger EA, Schacter DL. Amygdala activity is associated with the successful encoding of item, but not source, information for positive and negative stimuli. Journal of Neuroscience. 2006; 26:2564-2570. [PubMed: 16510734]

Kelley AE, Domesick VB, Nauta WJ. The amygdalostriatal projection in the rat - an anatomical study by anterograde and retrograde tracing methods. Neuroscience. 1982; 7:615-630. [PubMed: 7070669]

Kesner RP, Ellis ME. Memory consolidation: brain region and neurotransmitter specificity. Neuroscience Letters. 1983; 39:295-300. [PubMed: 6138739]

Kilpatrick L, Cahill L. Modulation of memory consolidation for olfactory learning by reversible inactivation of the basolateral amygdala. Behavioral Neuroscience. 2003; 117:184-188. [PubMed: 12619920]

Krauseneck T, Padberg F, Roozendaal B, Grathwohl M, Weis F, Hauer D, Kaufmann I, Schmoekel M, Schelling G. A $\beta$-adrenergic antagonist reduces traumatic memories and PTSD symptoms in female but not in male patients after cardiac surgery. Psychological Medicine. 2010; 40:861-860. [PubMed: 19691871]

Kuhlman S, Kirschbaum C, Wolf OT. Effects of oral cortisol treatment in healthy young women on memory retrieval of negative and neutral words. Neurobiology of Learning and Memory. 2005a; 83:158-162.

Kuhlman S, Piel M, Wolf OT. Impaired memory retrieval after psychosocial stress in healthy young men. Journal of Neuroscience. 2005b; 25:2977-2982.

Kuhlman S, Wolf OT. Arousal and cortisol interact in modulating memory consolidation in healthy young men. Behavioral Neuroscience. 2006; 120:217-223. [PubMed: 16492134]

LaBar KS, Cabezza R. Cognitive neuroscience of emotional memory. Nature Reviews Neuroscience. 2006; 7:54-64.

LaLumiere RT, Buen TV, McGaugh JL. Posttraining intra-basolateral amygdala infusions of norepinephrine enhance consolidation of memory for contextual fear conditioning. Journal of Neuroscience. 2003; 23:6754-6758. [PubMed: 12890768]

LaLumiere RT, Nawar EM, McGaugh JL. Modulation of memory consolidation by the basolateral amygdala or nucleus accumbens shell requires concurrent dopamine receptor activation in both brain regions. Learning \&Memory. 2005; 12:296-301. [PubMed: 15930508] 
LaLumiere RT, Nguyen L, McGaugh JL. Posttraining intra-basolateral amygdala infusions of dopamine modulate consolidation of inhibitory avoidance memory: involvement of noradrenergic and cholinergic systems. European Journal of Neuroscience. 2004; 20:2804-2810. [PubMed: 15548223]

Lashley KS. The effect of strychnine and caffeine upon rate of learning. Psychobiology. 1917; 1:141170.

Ledgerwood L, Richardson R, Cranney J. Effects of D-cycloserine on extinction of conditioned freezing. Behavioral Neuroscience. 2003; 117:341-349. [PubMed: 12708530]

Ledgerwood L, Richardson R, Cranney J. D-cycloserine facilitates extinction of learned fear: effects on reacquisition and generalized extinction. Biological Psychiatry. 2005; 57:841-847. [PubMed: 15820704]

Lee I, Kesner RP. Time-dependent relationship between the dorsal hippocampus and the prefrontal cortex in spatial memory. Journal of Neuroscience. 2003; 23:1517-1523. [PubMed: 12598640]

Lennartz RC, Hellems KL, Mook ER, Gold PE. Inhibitory avoidance impairments induced by intraamygdala propranolol are reversed by glutamate but not glucose. Behavioral Neuroscience. 1996; 110:1033-1039. [PubMed: 8919006]

Levy F, Farrow M. Working memory in ADHD: prefrontal/parietal connections. Current Drug Targets. 2001; 2:347-352. [PubMed: 11732636]

Li BM, Mao ZM, Wang M, Mei ZT. Alpha-2 adrenergic modulation of prefrontal cortical neuronal activity related to spatial working memory in monkeys. Neuropsychopharmacology. 1999; 21:601-610. [PubMed: 10516956]

Liang, KC. Epinephrine modulation of memory: amygdala activation and regulation of long-term memory storage. In: Gold, PE.; Greenough, WT., editors. Memory consolidation: essays in honor of James L McGaugh. Washington, D.C: American Psychological Association; 2001. p. 165-183.

Liang KC, Bennett C, McGaugh JL. Peripheral epinephrine modulates the effects of posttraining amygdala stimulation on memory. Behavioral Brain Research. 1985; 15:93-100.

Liang KC, Chen L, Huang TE. The role of amygdala norepinephrine in memory formation: involvement in the memory enhancing effect of peripheral epinephrine. Chinese Journal of Physiology. 1995; 38:81-91. [PubMed: 8697902]

Liang KC, Hu SJ, Chang SH. Formation and retrieval of inhibitory avoidance memory: differential roles of glutamate receptors in the amygdala and medial prefrontal cortex. Chinese Journal of Physiology. 1996; 39:155-166. [PubMed: 8955562]

Liang KC, Juler RG, McGaugh JL. Modulating effects of post-training epinephrine on memory: involvement of the amygdala noradrenergic system. Brain Research. 1986; 368:125-133. [PubMed: 3955350]

Liang KC, Lee EH. Intra-amygdala injections of corticotropin releasing factor facilitate inhibitory avoidance learning and reduce exploratory behavior in rats. Psychopharmacology (Berlin). 1988; 96:232-236. [PubMed: 3148150]

Liang KC, McGaugh JL. Lesions of the stria terminalis attenuate the enhancing effect of post-training epinephrine on retention of an inhibitory avoidance response. Behavioral Brain Research. 1983; 9:49-58.

Liang KC, McGaugh JL, Yao HY. Involvement of amygdala pathways in the influence of posttraining amygdala norepinephrine and peripheral epinephrine on memory storage. Brain Research. 1990; 508:225-233. [PubMed: 2306613]

Lidow MS, Koh PO, Arnsten AFT. D1 dopamine receptors in the mouse prefrontal cortex: immunocytochemical and cognitive neuropharmacological analyses. Synapse. 2003; 47:101-108. [PubMed: 12454947]

Likhtik E, Pelletier JG, Paz R, Paré D. Prefrontal control of the amygdala. Journal of Neuroscience. 2005; 25:7429-7437. [PubMed: 16093394]

Lupien SJ, Gillin CJ, Hauger RL. Working memory is more sensitive than declarative memory to the acute effects of corticosteroids: a dose-response study in humans. Behavioral Neuroscience. 1999; 113:420-430. [PubMed: 10443770]

Lupien SJ, McEwen BS. The acute effects of corticosteroids on cognition: integration of animal and human model studies. Brain Research Reviews. 1997; 24:1-27. [PubMed: 9233540] 
Lyons DM, Lopez JM, Yang C, Schatzberg AF. Stress-level cortisol treatment impairs inhibitory control of behavior in monkeys. Journal of Neuroscience. 2000; 20:7816-7821. [PubMed: 11027246]

Malin EL, Ibrahim DY, Tu JW, McGaugh JL. Involvement of the rostral anterior cingulate cortex in consolidation of inhibitory avoidance memory: interaction with the basolateral amygdala. Neurobiology of Learning and Memory. 2007; 87:295-302. [PubMed: 17079169]

Malin E, McGaugh JL. Differential involvement of the hippocampus, anterior cingulate cortex and basolateral amygdala in memory for context and footshock. Proceedings of the National Academy of Sciences of the United States of America. 2006; 103:1959-1963. [PubMed: 16446423]

McCarty R, Gold PE. Plasma catecholamines: effects of footshock level and hormonal modulators of memory storage. Hormones and Behavior. 1981; 15:168-182. [PubMed: 6265338]

McDonald AJ. Organization of amygdaloid projections to the prefrontal cortex and associated striatum in the rat. Neuroscience. 1991; 44:1-14. [PubMed: 1722886]

McDonald RJ, White NM. A triple dissociation of memory systems: hippocampus, amygdala and dorsal striatum. Behavioral Neuroscience. 1993; 107:3-22. [PubMed: 8447956]

McEwen BS, Sapolsky RM. Stress and cognitive function. Current Opinion in Neurobiology. 1995; 5:205-216. [PubMed: 7620309]

McEwen BS, Weiss JM, Schwartz LS. Selective retention of corticosterone by limbic structors in the rat brain. Nature. 1968; 220:911-912. [PubMed: 4301849]

McGaugh JL. Time-dependent processes in memory storage. Science. 1966; 153:1351-1358. [PubMed: 5917768]

McGaugh JL. Drug facilitation of learning and memory. Annual Review of Pharmacology. 1973; 13:229-241.

McGaugh JL. Hormonal influences on memory. Annual Review of Psychology. 1983; 34:297-323.

McGaugh JL. Involvement of hormonal and neuromodulatory systems in the regulation of memory storage. Annual Review of Neuroscience. 1989; 12:255-287.

McGaugh JL. Memory: a century of consolidation. Science. 2000; 287:248-251. [PubMed: 10634773]

McGaugh JL. Memory consolidation and the amygdala: a systems perspective. Trends in Neuroscience. 2002; 25:456-461.

McGaugh, JL. Memory and emotion: the making of lasting memories. London: Weidenfeld and Nicolson The Orion House Group Ltd; New York: Columbia University Press; 2003.

McGaugh JL. The amygdala modulates the consolidation of memories of emotionally arousing experiences. Annual Review of Neuroscience. 2004; 27:1-28.

McGaugh JL. Emotional arousal and enhanced amygdala activity: new evidence for the old perseveration-consolidation hypothesis. Learning \&Memory. 2005; 12:77-79. [PubMed: 15805304]

McGaugh JL, Cahill L. Interaction of neuromodulatory systems in modulating memory storage. Behavioral Brain Research. 1997; 83:31-38.

McGaugh, JL.; Ferry, B.; Vazdarjanova, A.; Roozendaal, B. Amygdala: role in modulation of memory storage. In: Aggleton, JP., editor. The amygdala. London: Oxford University Press; 2000. p. 391-423.

McGaugh, JL.; Gold, PE. Hormonal modulation of memory. In: Brush, RB.; Levine, S., editors. Psychoendocrinology. New York: Academic Press; 1989. p. 305-339.

McGaugh, JL.; Herz, MJ. Memory consolidation. San Francisco: Albion Publishing Company; 1972.

McGaugh JL, Introini-Collison IB, Nagahara AH. Memory-enhancing effects of posttraining naloxone: involvement of $\beta$-noradrenergic influences in the amygdaloid complex. Brain Research. 1988; 446:37-49. [PubMed: 2836028]

McGaugh JL, Introini-Collison IB, Nagahara AH, Cahill L, Brioni JD, Castellano C. Involvement of the amygdaloid complex in neuromodulatory influences on memory storage. Neuroscience \&Biobehavioral Reviews. 1990; 14:425-431. [PubMed: 1981091] 
McGaugh JL, Izquierdo I. The contribution of pharmacology to research on the mechanisms of memory formation. Trends in Pharmacological Sciences. 2000; 21:208-210. [PubMed: 10838606]

McGaugh JL, Petrinovich LF. Effects of drugs on learning and memory. International Review of Neurobiology. 1965; 8:139-196. [PubMed: 5321471]

McGaugh JL, Roozendaal B. Role of adrenal stress hormones in forming lasting memories in the brain. Current Opinion in Neurobiology. 2002; 12:205-210. [PubMed: 12015238]

McGaugh JL, Roozendaal B. Drug enhancement of memory consolidation: historical perspective and neurobiological implications. Psychopharmacology (Berlin). 2009; 202:3-14. [PubMed: 18704369]

McIntyre CK, Hatfield T, McGaugh JL. Amygdala norepinephrine levels after training predict inhibitory avoidance retention performance in rats. European Journal of Neuroscience. 2002; 16:1223-1226. [PubMed: 12405982]

McIntyre CK, Miyashita T, Setlow B, Marjon KD, Steward O, Guzowski JF, McGaugh JL. Memoryinfluencing intra-basolateral amygdala drug infusions modulate expression of Arc protein in the hippocampus. Proceedings of the National Academy of Science of the United States of America. 2005; 102:10718-10723.

McNay EC, Gold PE. Memory modulation across neural systems: intra-amygdala glucose reverses deficits caused by intraseptal morphine on a spatial task but not on an aversive task. Journal of Neuroscience. 1998; 18:3853-3858. [PubMed: 9570814]

McReynolds JR, Donowho K, Abdi A, McGaugh JL, Roozendaal B, McIntyre CK. Memoryenhancing corticosterone treatment increases amygdala norepinephrine and Arc protein expression in hippocampal synaptic fractions. Neurobiology of Learning and Memory. 2010; 93:312-321. [PubMed: 19932757]

Messier C, White NM. Contingent and non-contingent actions of sucrose and saccharin reinforcers: effects on taste preference and memory. Physiology \&Behavior. 1984; 32:195-203. [PubMed: 6718546]

Messier C, White NM. Memory improvement by glucose, fructose, and two glucose analogs: a possible effect on peripheral glucose transport. Behavioral and Neural Biology. 1987; 48:104127. [PubMed: 3307740]

Messing RB, Jensen RA, Martinez JL Jr, Spiehler VR, Vasquez BJ, Soumireu-Mourat B, Liang KC, McGaugh JL. Naloxone enhancement of memory. Behavioral and Neural Biology. 1979; 27:266-275. [PubMed: 518457]

Miasnikov AA, Chen JC, Weinberger NM. Rapid induction of specific associative behavioral memory by stimulation of the nucleus basalis in the rat. Neurobiology of Learning and Memory. 2006; 86:47-65. [PubMed: 16466937]

Miasnikov AA, McLin D 3rd, Weinberger NM. Muscarinic dependence of nucleus basalis induced conditioned receptive field plasticity. NeuroReport. 2001; 12:1537-1542. [PubMed: 11388444]

Miranda MI, LaLumiere RT, Buen TV, Bermudez-Rattoni F, McGaugh JL. Blockade of noradrenergic receptors in the basolateral amygdala impairs taste memory. European Journal of Neuroscience. 2003; 18:2605-2610. [PubMed: 14622162]

Miranda MI, McGaugh JL. Enhancement of inhibitory avoidance and conditioned taste aversion memory with insular cortex infusions of 8-Br-cAMP: involvement of the basolateral amygdala. Learning \&Memory. 2004; 11:312-317. [PubMed: 15169861]

Miranda MI, Quirarte GL, Rodriguez-Garcia G, McGaugh JL, Roozendaal B. Glucocorticoids enhance taste aversion memory via actions in the insular cortex and basolateral amygdala. Learning \&Memory. 2008; 15:468-476. [PubMed: 18612067]

Miyashita T, Williams CL. Glutamatergic transmission in the nucleus of the solitary tract modulates memory through influences on amygdala noradrenergic systems. Behavioral Neuroscience. 2002; 116:13-21. [PubMed: 11895175]

Mizoguchi K, Ishige A, Takeda S, Aburada M, Tabita T. Endogenous glucocorticoids are essential for maintaining prefrontal cortical cognitive function. Journal of Neuroscience. 2004; 24:5492-5499. [PubMed: 15201321] 
Morrow BA, Roth RH, Elsworth JD. TMT, a predator odor, elevates mesoprefrontal dopamine metabolic activity and disrupts short-term working memory in the rat. Brain Research Bulletin. 2000; 52:519-523. [PubMed: 10974491]

Müller GE, Pilzecker A. Experimentelle Beitrage zur Lehre vom Gedachtniss. Zeitung Psychology. $1900 ; 1: 1-288$.

Mulder AB, Hodenpijl MG, Lopes da Silva FH. Electrophysiology of the hippocampal and amygdaloid projections to the nucleus accumbens of the rat: convergence, segregation, and interaction of inputs. Journal of Neuroscience. 1998; 18:5095-5102. [PubMed: 9634575]

Murphy BL, Arnsten AFT, Goldman-Rakic PS, Roth RH. Increased dopamine turnover in the prefrontal cortex impairs spatial working memory performance in rats and monkeys. Proceedings of the National Academy of Sciences of the United States of America. 1996; 93:1325-1329. [PubMed: 8577763]

Nakamura S, Tepper JM, Young SJ, Ling N, Groves PM. Noradrenergic terminal excitability: effects of opioids. Neurosciences Letters. 1982; 30:57-62.

Nielson KA, Jensen RA. Beta-adrenergic receptor antagonist antihypertensive medications impair arousal-induced modulation of working memory in elderly humans. Behavioral and Neural Biology. 1994; 62:190-200. [PubMed: 7857241]

O'Carroll RE, Drysdale E, Cahill L, Shajahan P, Ebmeier KP. Stimulation of the noradrenergic system enhances and blockade reduces memory for emotional material in man. Psychological Medicine. 1999; 29:1083-1088. [PubMed: 10576300]

Oei NYL, Elzinga BM, Wolf OT, Ruiter MB, Damouiseaux JS, Kuijer JPA, Veltman DJ, Scheltens P, Rombouts SARB. Glucocorticoids decrease hippocampal and prefrontal activation during declarative memory retrieval in young men. Brain Imaging and Behavior. 2007; 1:31-41. [PubMed: 19946603]

Oitzl MS, de Kloet ER. Selective corticosteroid antagonists modulate specific aspects of spatial orientation learning. Behavioral Neuroscience. 1992; 108:62-71. [PubMed: 1313244]

Okuda S, Roozendaal B, McGaugh JL. Glucocorticoid effects on object recognition memory require training-associated emotional arousal. Proceedings of the National Academy of Sciences of the United States of America. 2004; 101:853-858. [PubMed: 14711996]

Oomura, Y.; Nakano, Y.; Lenard, L.; Nishino, H.; Aou, S. Catecholaminergic and opioid mechanisms in conditioned food intake behavior of the monkey amygdala. In: Woody, CD.; Alkon, DL.; McGaugh, JL., editors. Cellular mechanisms of conditioning and behavioral plasticity. New York: Plenum; 1988. p. 109-118.

Packard MG, Cahill L. Affective modulation of multiple memory systems. Current Opinion in Neurobiology. 2001; 11:752-756. [PubMed: 11741029]

Packard MG, Cahill L, McGaugh JL. Amygdala modulation of hippocampal-dependent and caudate nucleus-dependent memory processes. Proceedings of the National Academy of Sciences of the United States of America. 1994; 91:8477-8481. [PubMed: 8078906]

Packard MG, Chen SA. The basolateral amygdala is a cofactor in memory enhancement produced by intrahippocampal glutamate injections. Psychobiology. 1999; 27:377-385.

Packard MG, Introini-Collison I, McGaugh JL. Stria terminalis lesions attenuate memory enhancement produced by intra-caudate nucleus injections of oxotremorine. Neurobiology of Learning and Memory. 1996; 65:278-282. [PubMed: 8616592]

Packard MG, Knowlton BJ. Learning and memory functions of the basal ganglia. Annual Review of Neuroscience. 2002; 25:563-593.

Packard MG, McGaugh JL. Double dissociation of fornix and caudate nucleus lesions on acquisition of two water maze tasks: further evidence for multiple memory systems. Behavioral Neuroscience. 1992; 106:439-446. [PubMed: 1616610]

Packard MG, McGaugh JL. Inactivation of hippocampus or caudate nucleus with lidocaine differentially affects expression of place and response learning. Neurobiology of Learning and Memory. 1996; 65:65-72. [PubMed: 8673408]

Packard MG, Teather L. Amygdala modulation of multiple memory systems: hippocampus and caudate-putamen. Neurobiology of Learning and Memory. 1998; 69:163-203. [PubMed: 9619995] 
Pakdel R, Rashidy-Pour A. Glucocorticoid-induced impairment of long-term memory retrieval in rats: an interaction with dopamine D2 receptors. Neurobiology of Learning and Memory. 2006; 85:300-306. [PubMed: 16442318]

Pape HC, Narayanan RT, Smid J, Stork O, Seidenbecher T. Theta activity in neurons and networks of the amygdala related to long-term fear memory. Hippocampus. 2005; 15:874-880. [PubMed: 16158424]

Paré D. Role of the basolateral amygdala in memory consolidation. Progress in Neurobiology. 2003; 70:409-420. [PubMed: 14511699]

Paré D, Collins DR, Pelletier JG. Amygdala oscillations and the consolidation of emotional memories. Trends in Cognitive Science. 2002; 6:306-314.

Paré D, Dong J, Gaudreau H. Amygdalo-entorhinal relations and their reflection in the hippocampal formation: generation of sharp potentials. Journal of Neuroscience. 1995; 15:2482-2503. [PubMed: 7891183]

Paré D, Gaudreau H. Projection cells and interneurons of the lateral and basolateral amygdala: distinct firing patterns and differential relation to theta and delta rhythms in conscious cats. Journal of Neuroscience. 1996; 16:3334-3350. [PubMed: 8627370]

Parent MB, McGaugh JL. Posttraining infusion of lidocaine into the amygdala basolateral complex impairs retention of inhibitory avoidance training. Brain Research. 1994; 661:97-103. [PubMed: 7834391]

Passani MB, Cangioli I, Baldi E, Bucherelli C, Mannaioni PF, Blandina P. Histamine $\mathrm{H}_{3}$ receptormediated impairment of contextual fear conditioning and in vivo inhibition of cholinergic transmission in the rat basolateral amygdala. European Journal of Neuroscience. 2001; 14:1-13. [PubMed: 11488943]

Pelletier JG, Likhtik E, Filali M, Paré D. Lasting increases in basolateral amygdala activity after emotional arousal: implications for facilitated consolidation of emotional memories. Learning \&Memory. 2005; 12:96-102. [PubMed: 15805308]

Pelletier JG, Paré D. Role of amygdala oscillations in the consolidation of emotional memories. Biological Psychiatry. 2004; 55:559-562. [PubMed: 15013823]

Perez-Jaranay JM, Vives F. Electrophysiological study of the response of medial prefrontal cortex neurons to stimulation of the basolateral nucleus of the amygdala in the rat. Brain Research. 1991; 564:97-101. [PubMed: 1777825]

Petrovich GD, Canteras NS, Swanson LW. Combinatorial amygdalar inputs to hippocampal domains and hypothalamic behavior systems. Brain Research Reviews. 2001; 38:247-289. [PubMed: 11750934]

Pikkarainen M, Ronko S, Savander V, Insausti R, Pitkanen A. Projections from the lateral, basal, and accessory basal nuclei of the amygdala to the hippocampal formation in rat. Journal of Comparative Neurology. 1999; 403:229-260. [PubMed: 9886046]

Pitkänen, A. Connectivity of the rat amygdaloid complex. In: Aggleton, JP., editor. The amygdala. London: Oxford University Press; 2000. p. 31-117.

Popescu AT, Popa D, Paré D. Coherent gamma oscillations couple the amygdala and striatum during learning. Nature Neuroscience. 2009; 12:801-807.

Popescu AT, Saghyan AA, Paré D. NMDA-dependent facilitation of corticostriatal plasticity by the amygdala. Proceedings of the National Academy of Sciences of the United States of America. 2007; 104:341-346. [PubMed: 17182737]

Power AE, McGaugh JL. Phthalic acid amygdalopetal lesion of the nucleus basalis magnocellularis induces reversible memory deficits in rats. Neurobiology of Learning and Memory. 2002; 77:373-388.

Power AE, McIntyre CK, Litmanovich A, McGaugh JL. Cholinergic modulation of memory in the basolateral amygdala involves activation of both $\mathrm{m} 1$ and $\mathrm{m} 2$ receptors. Behavioral Pharmacology. 2003b; 14:207-213.

Power AE, Roozendaal B, McGaugh JL. Glucocorticoid enhancement of memory consolidation in the rat is blocked by muscarinic receptor antagonism in the basolateral amygdala. European Journal of Neuroscience. 2000; 12:3481-3487. [PubMed: 11029617] 
Power AE, Thal LJ, McGaugh JL. Lesions of the nucleus basalis magnocellularis induced by 192 IgGsaporin block memory enhancement with posttraining norepinephrine in the basolateral amygdala. Proceedings of the National Academy of Sciences of the United States of America. 2002; 99:2325-2329.

Power AE, Vazdarjanova A, McGaugh JL. Muscarinic cholinergic influences in memory consolidation. Neurobiology of Learning and Memory. 2003a; 80:178-183. [PubMed: 14521862]

Price, JL. Toward a consistent terminology for the amygdaloid complex. In: Ben-Ari, Y., editor. The amygdaloid complex. Amsterdam: Elsevier, North Holland; 1981. p. 13-18.

$\mathrm{Pu}$ Z, Krugers HJ, Joëls M. Beta-adrenergic facilitation of synaptic plasticity in the rat basolateral amygdala in vitro is gradually reversed by corticosterone. Learning \& Memory. 2009; 16:155160. [PubMed: 19196909]

Quillfeldt JA, Zanatta MS, Schmitz PK, Quevedo J, Schaeffer E, Lima JB, Medina JH, Izquierdo I. Different brain areas are involved in memory expression at different times from training. Neurobiology of Learning and Memory. 1996; 66:97-102. [PubMed: 8946402]

Quirarte GL, Galvez R, Roozendaal B, McGaugh JL. Norepinephrine release in the amygdala in response to footshock and opioid peptidergic drugs. Brain Research. 1998; 808:134-140. [PubMed: 9767150]

Quirarte GL, Roozendaal B, McGaugh JL. Glucocorticoid enhancement of memory storage involves noradrenergic activation in the basolateral amygdala. Proceedings of the National Academy of Sciences of the United States of America. 1997; 94:14048-14053. [PubMed: 9391150]

Ragozzino ME, Gold PE. Task-dependent effects of intra-amygdala morphine injections: attenuation by intra-amygdala glucose injections. Journal of Neuroscience. 1994; 14:7478-7485. [PubMed: 7996189]

Ramos BP, Colgan L, Nou E, Ovadia S, Wilson SR, Arnsten AF. The beta-1 adrenergic antagonist, betaxolol, improves working memory performance in rats and monkeys. Biological Psychiatry. 2005; 58:894-900. [PubMed: 16043136]

Rasch B, Spalek K, Buholzer S, Luechinger R, Boesiger P, Papassotiropoulos A, de Quervain DJF. A genetic variation of the noradrenergic system is related to differential amygdala activation during encoding of emotional memories. Proceedings of the National Academy of Sciences of the United States of America. 2009; 106:19191-19196. [PubMed: 19826083]

Rashidy-Pour A, Razvani ME. Unilateral reversible inactivations of the nucleus tractus solitarius and amygdala attenuate the effects of bombesin on memory storage. Brain Research. 1998; 814:127132. [PubMed: 9838077]

Rashidy-Pour A, Sadeghi H, Taherain AA, Vafaei AA, Fathollahi Y. The effects of acute restraint stress and dexamethasone on retrieval of long-term memory in rats: an interaction with opiate system. Behavioral Brain Research. 2004; 154:193-198.

Ressler KJ, Paschall G, Zhou XL, Davis M. Regulation of synaptic plasticity genes during consolidation of fear conditioning. Journal of Neuroscience. 2002; 22:7892-7902. [PubMed: 12223542]

Reul JM, de Kloet ER. Two receptor systems for corticosterone in rat brain: microdistribution and differential occupation. Endocrinology. 1985; 117:2505-2511. [PubMed: 2998738]

Reul JMHM, de Kloet ER, van Sluys FA, Rijnberk A, Rothuizen J. Binding characteristics of mineralocorticoid and glucocorticoid receptors in dog brain and pituitary. Endocrinology. 1990; 127:907-915. [PubMed: 2164924]

Ricardo JA, Koh ET. Anatomical evidence of direct projections from the nucleus of the solitary tract to the hypothalamus, amygdala, and other forebrain structures in the rat. Brain Research. 1978; 153:1-26. [PubMed: 679038]

Riedel G, Micheau J, Lam AG, Roloff EL, Martin SJ, Bridge H, de Hoz L, Poeschel B, McCulloch J, Morris RG. Reversible neural inactivation reveals hippocampal participation in several memory processes. Nature Neuroscience. 1999; 2:898-905.

Ritchey M, Dolcos F, Cabeza R. Role of amygdala connectivity in the persistence of emotional memories over time: an event-related fMRI investigation. Cerebral Cortex. 2008; 18:2494-2504. [PubMed: 18375529] 
Roesler R, Lessa D, Venturella R, Vianna MR, Luft T, Henriques JA, Izquierdo I, Schwartsmann G. Bombesin/gastrin-releasing peptide receptors in the basolateral amygdala regulate memory consolidation. European Journal of Neuroscience. 2004; 19:1041-1045. [PubMed: 15009151]

Roesler R, Roozendaal B, McGaugh JL. Basolateral amygdala lesions block the memory-enhancing effect of 8-Br-cAMP infused into the entorhinal cortex of rats after training. European Journal of Neuroscience. 2002; 15:905-910. [PubMed: 11906532]

Roozendaal B. Glucocorticoids and the regulation of memory consolidation. Psychoneuroendocrinology. 2000; 25:213-238. [PubMed: 10737694]

Roozendaal B. Stress and memory: opposing effects of glucocorticoids on memory consolidation and memory retrieval. Neurobiology of Learning and Memory. 2002; 78:578-595. [PubMed: 12559837]

Roozendaal, B. Norepinephrine and long-term memory function. In: Ordway, GA.; Schwartz, MA.; Frazer, A., editors. Brain norepinephrine: neurobiology and therapeutics. Cambridge: Cambridge University Press; 2007. p. 236-274.

Roozendaal B, Brunson KL, Holloway BL, McGaugh JL, Baram TZ. Involvement of stress-released corticotropin-releasing hormone in the basolateral amygdala in regulating memory consolidation. Proceedings of the National Academy of Sciences of the United States of America. 2002b; 99:13908-13913. [PubMed: 12361983]

Roozendaal B, Carmi O, McGaugh JL. Adrenocortical suppression blocks the memory-enhancing effects of amphetamine and epinephrine. Proceedings of the National Academy of Sciencs of the United States of America. 1996a; 93:1429-1433.

Roozendaal B, Castello N, Vedana G, Barsegyan A, McGaugh JL. Noradrenergic activation of the basolateral amygdala modulates consolidation of object recognition memory. Neurobiology of Learning and Memory. 2008b; 90:576-579. [PubMed: 18657626]

Roozendaal B, de Quervain DJF, Ferry B, Setlow B, McGaugh JL. Basolateral amygdala-nucleus accumbens interactions in mediating glucocorticoid effects on memory consolidation. Journal of Neuroscience. 2001; 21:2518-2525. [PubMed: 11264325]

Roozendaal B, de Quervain DJ-F, Schelling G, McGaugh JL. A systemically administered $\beta$ adrenoceptor antagonist blocks corticosterone-induced impairment of contextual memory retrieval in rats. Neurobiology of Learning and Memory. 2004a; 81:150-154. [PubMed: 14990235]

Roozendaal B, Griffith QK, Buranday J, de Quervain DJF, McGaugh JL. The hippocampus mediates glucocorticoid-induced impairment of spatial memory retrieval: dependence on the basolateral amygdala. Proceedings of the National Academy of Sciences of the United States of America. 2003; 100:1328-1333. [PubMed: 12538851]

Roozendaal B, Hahn EL, Nathan SV, de Quervain DJF, McGaugh JL. Glucocorticoid effects on memory retrieval require concurrent noradrenergic activity in the hippocampus and basolateral amygdala. Journal of Neuroscience. 2004b; 24:8161-8169. [PubMed: 15371517]

Roozendaal B, Hui GK, Hui IR, Berlau DJ, McGaugh JL, Weinberger NM. Basolateral amygdala noradrenergic activity mediates corticosterone-induced enhancement of auditory fear conditioning. Neurobiology of Learning and Memory. 2006b; 86:249-255. [PubMed: 16630730]

Roozendaal B, Lengvilas R, McGaugh JL, Civelli O, Reinscheid RK. Orphanin FQ-nociceptin interactions with the basolateral amygdala noradrenergic system in memory consolidation. Learning \&Memory. 2007; 14:29-35. [PubMed: 17202427]

Roozendaal B, McEwen BS, Chattarji S. Stress, memory and the amygdala. Nature Reviews Neuroscience. 2009a; 10:423-433.

Roozendaal B, McGaugh JL. Amygdaloid nuclei lesions differentially affect glucocorticoid-induced memory enhancement in an inhibitory avoidance task. Neurobiology of Learning and Memory. 1996a; 65:1-8. [PubMed: 8673403]

Roozendaal B, McGaugh JL. The memory-modulatory effects of glucocorticoids depend on an intact stria terminalis. Brain Research. 1996b; 709:243-250. [PubMed: 8833760]

Roozendaal B, McGaugh JL. Glucocorticoid receptor agonist and antagonist administration into the basolateral but not central amygdala modulates memory storage. Neurobiology of Learning and Memory. 1997a; 67:176-179. [PubMed: 9075247] 
Roozendaal B, McGaugh JL. Basolateral amygdala lesions block the memory-enhancing effect of glucocorticoid administration in the dorsal hippocampus of rats. European Journal of Neuroscience. 1997b; 9:76-83. [PubMed: 9042571]

Roozendaal B, McReynolds JR, McGaugh JL. The basolateral amygdala interacts with the medial prefrontal cortex in regulating glucocorticoid effects on working memory impairment. Journal of Neuroscience. 2004c; 24:1385-1392. [PubMed: 14960610]

Roozendaal B, McReynolds JR, Van der Zee EA, Lee S, McGaugh JL, McIntyre CK. Glucocorticoid effects on memory consolidation depend on functional interactions between the medial prefrontal cortex and basolateral amygdala. Journal of Neuroscience. 2009b; 29:14299-14308. [PubMed: 19906977]

Roozendaal B, Nguyen BT, Power A, McGaugh JL. Basolateral amygdala noradrenergic influence enables enhancement of memory consolidation induced by hippocampal glucocorticoid receptor activation. Proceedings of the National Academy of Sciences of the United States of America. 1999b; 96:11642-11647. [PubMed: 10500230]

Roozendaal B, Portillo-Marquez G, McGaugh JL. Basolateral amygdala lesions block glucocorticoidinduced modulation of memory for spatial learning. Behavioral Neuroscience. 1996b; 110:10741083. [PubMed: 8919010]

Roozendaal B, Quirarte GL, McGaugh JL. Glucocorticoids interact with the basolateral amygdala $\beta$ adrenoceptor-cAMP/PKA system in influencing memory consolidation. European Journal of Neuroscience. 2002a; 15:553-560. [PubMed: 11876783]

Roozendaal B, Okuda S, Van der Zee EA, McGaugh JL. Glucocorticoid enhancement of memory requires arousal-induced noradrenergic activation in the basolateral amygdala. Proceedings of the National Academy of Sciences of the United States of America. 2006a; 103:6741-6746. [PubMed: 16611726]

Roozendaal B, Schelling G, McGaugh JL. Corticotropin-releasing factor in the basolateral amygdala enhances memory consolidation via an interaction with the $\beta$-adrenoceptor-cAMP pathway: dependence on glucocorticoid receptor activation. Journal of Neuroscience. 2008a; 28:66426651. [PubMed: 18579737]

Roozendaal B, Williams CL, McGaugh JL. Glucocorticoid receptor activation in the rat nucleus of the solitary tract facilitates memory consolidation: involvement of the basolateral amygdala. European Journal of Neuroscience. 1999a; 11:1317-1323. [PubMed: 10103127]

Rosenkranz JA, Grace AA. Cellular mechanisms of infralimbic and prelimbic prefrontal cortical inhibition and dopaminergic modulation of basolateral amygdala neurons in vivo. Journal of Neuroscience. 2002; 22:324-337. [PubMed: 11756516]

Rowe JB, Toni I, Josephs O, Frackowiak RS, Passingham RE. The prefrontal cortex: response selection of maintenance within working memory? Science. 2000; 288:1656-1660. [PubMed: 10834847]

Runyan JD, Dash PK. Intra-medial prefrontal administration of SCH-23390 attenuates ERK phosphorylation and long-term memory for trace fear conditioning in rats. Neurobiology of Learning and Memory. 2004; 82:65-70. [PubMed: 15341790]

Sacchetti B, Lorenzini CA, Baldi E, Tassoni G, Bucherelli C. Auditory thalamus, dorsal hippocampus, basolateral amygdala, and perirhinal cortex role in the consolidation of conditioned freezing to context and to acoustic conditioned stimulus in the rat. Journal of Neuroscience. 1999; 19:95709578. [PubMed: 10531459]

Sajadi AA, Samaei SA, Rashidy-Pour A. Intra-hippocampal microinjections of anisomycin did not block glucocorticoid-induced impairment of memory retrieval in rats: an evidence for nongenomic effects of glucocorticoids. Behavioral Brain Research. 2006; 173:158-162.

Salinas JA, Introini-Collison IB, Dalmaz C, McGaugh JL. Posttraining intra-amygdala infusions of oxotremorine and propranolol modulate storage of memory for reductions in reward magnitude. Neurobiology of Learning and Memory. 1997; 68:51-59. [PubMed: 9195589]

Salinas JA, McGaugh JL. Muscimol induces retrograde amnesia for changes in reward magnitude. Neurobiology of Learning and Memory. 1995; 63:277-285. [PubMed: 7670841] 
Sandi C, Rose SPR. Corticosterone enhances long-term potentiation in one-day-old chicks trained in a weak passive avoidance learning paradigm. Brain Research. 1994; 647:106-112. [PubMed: 8069692]

Sandi C, Pinelo-Nava MT. Stress and memory: behavioral effects and neurobiological mechanisms. Neural Plasticity. 2007; 2007:78970. [PubMed: 18060012]

Sato T, Tanaka K, Teramoto T, Ohnishi Y, Hirate K, Irifune M, Nishikawa T. Effect of pretraining administration of NC-1900, a vasopressin fragment analog, on memory performance in non- or CO2-amnesic mice. Pharmacology, Biochemistry \&Behavior. 2004; 78:309-317.

Sawaguchi T, Goldman-Rakic PS. D1 dopamine receptors in prefrontal cortex: involvement in working memory. Science. 1991; 251:947-950. [PubMed: 1825731]

Schafe GE, LeDoux JE. Memory consolidation of auditory Pavlovian fear conditioning requires protein synthesis and protein kinase A in the amygdala. Journal of Neuroscience. 2000; 20:RC96. [PubMed: 10974093]

Schlesinger K, Pelleymounter MA, van de Kamp J, Bader DL, Stewart KM, Chase TN. Substance P facilitation of memory: effects in an appetitively motivated learning task. Behavioral and Neural Biology. 1986; 45:230-239. [PubMed: 2421708]

Schoofs D, Preuss D, Wolf OT. Psychosocial stress induces working memory impairments in an nback paradigm. Psychoneuroendocrinology. 2008; 33:643-653. [PubMed: 18359168]

Schreurs J, Seelig T, Schulman H. $\beta 2$-adrenergic receptors on peripheral nerves. Journal of Neurochemistry. 1986; 46:294-296. [PubMed: 2999336]

Schroeder JP, Packard MG. Posttraining intra-basolateral amygdala scopolamine impairs food- and amphetamine-induced conditioned place preferences. Behavioral Neuroscience. 2002; 116:922927. [PubMed: 12369812]

Schroeder JP, Packard MG. Systemic or intra-amygdala injections of glucose facilitate memory consolidation for extinction of drug-induced conditioned reward. European Journal of Neuroscience. 2003; 17:1482-1488. [PubMed: 12713651]

Schroeder JP, Packard MG. Facilitation of memory for extinction of drug-induced conditioned reward: role of amygdala and acetylcholine. Learning \& Memory. 2004; 11:641-647. [PubMed: 15466320]

Schwabe L, Bohringer A, Chatterjee M, Schachinger H. Effect of pre-learning stress on memory for neutral, positive and negative words: differential rols of cortisol and autonomic arousal. Neurobiology of Learning and Memory. 2008; 90:44-53. [PubMed: 18334304]

Schwabe L, Römer S, Richter S, Dockendorf S, Bilak B, Schachinger H. Stress effects on declarative memory retrieval are blocked by a $\beta$-adrenoceptor antagonist in humans. Psychoneuroendocrinology. 2009; 34:446-454. [PubMed: 19028019]

Schwabe L, Wolf OT. The context counts: Congruent learning and testing environments prevent memory retrieval impairment following stress. Cognitive Affective and Behavioral Neuroscience. 2009; 9:229-236.

Seamans JK, Floresco SB, Phillips AG. D1 receptor modulation of hippocampal-prefrontal cortical circuits integrating spatial memory with executive functions in the rat. Journal of Neuroscience. 1998; 18:1613-1621. [PubMed: 9454866]

Setlow B, Roozendaal B, McGaugh JL. Involvement of a basolateral amygdala complex - nucleus accumbens pathway in glucocorticoid-induced modulation of memory storage. European Journal of Neuroscience. 2000; 12:367-375. [PubMed: 10651892]

Smeets T, Otgaar H, Candel I, Wolf OT. True or false? Memory is differentially affected by stressinduced cortisol elevations and sympathetic activity at consolidation and retrieval. Psychoneuroendocrinology. 2008; 33:1378-1386. [PubMed: 18790572]

Smith AP, Stephan KE, Rugg MD, Dolan RJ. Task and content modulate amygdala-hippocampal connectivity in emotional retrieval. Neuron. 2006; 49:631-638. [PubMed: 16476670]

Soetens E, Casaer S, D’Hooge R, Hueting JE. Effect of amphetamine on long-term retention of verbal material. Psychopharmacology (Berlin). 1995; 119:155-162. [PubMed: 7659762]

Soetens E, D’Hooge R, Hueting JE. Amphetamine enhances human-memory consolidation. Neuroscience Letters. 1993; 161:9-12. [PubMed: 8255556] 
Southwick S, Davis M, Horner B, Cahill L, Morgan D, Gold P, Bremner J, Charney D. Relationship of enhanced norepinephrine activity during memory consolidation to enhanced long-term memory in humans. American Journal of Psychiatry. 2002; 159:1420-1422. [PubMed: 12153837]

Squire LR, Clark RE, Knowlton BJ. Retrograde amnesia. Hippocampus. 2001; 11:50-56. [PubMed: 11261772]

Stern CE, Sherman SJ, Kirchhoff BA, Hasselmo ME. Medial temporal and prefrontal contributions to working memory tasks with novel and familiar stimuli. Hippocampus. 2001; 11:337-346. [PubMed: 11530838]

Sternberg DB, Isaacs K, Gold PE, McGaugh JL. Epinephrine facilitation of appetitive learning: attenuation with adrenergic receptor antagonists. Behavioral and Neural Biology. 1985; 44:447453. [PubMed: 4084188]

Strange BA, Dolan RJ. $\beta$-adrenergic modulation of emotional memory-evoked human amygdala and hippocampal responses. Proceedings of the National Academy of Sciences of the United States of America. 2004; 101:11454-11458. [PubMed: 15269349]

Stratton LO, Petrinovich LF. Post-trial injections of an anticholinesterase drug and maze learning in two strains of rats. Psychopharmacologia. 1963; 5:47-54. [PubMed: 14082381]

Sutanto W, de Kloet ER. Species-specificity of corticosteroid receptors in hamster and rat. Endocrinology. 1987; 121:1405-1411. [PubMed: 3653033]

Talley CP, Clayborn H, Jewel E, McCarty R, Gold PE. Vagotomy attenuates effects of L-glucose but not of D-glucose on spontaneous alternation performance. Physiology \& Behavior. 2002; 77:243-249. [PubMed: 12419400]

Tam SY, Roth RH. Selective increase in dopamine metabolism in the prefrontal cortex by the anxiogenic beta-carboline FG 7142. Biochemical Pharmacology. 1985; 34:1595-1598. [PubMed: 3838896]

Tasker JG, Di S, Malcher-Lopes R. Minireview: rapid glucocorticoid signaling via membraneassociated receptors. Endocrinology. 2006; 147:5549-5556. [PubMed: 16946006]

Taylor JR, Birnbaum S, Ubriani R, Arnsten AFT. Activation of cAMP-dependent protein kinase A in prefrontal cortex impairs working memory performance. Journal of Neuroscience. 1999; 19:RC23. [PubMed: 10479716]

Tollenaar MS, Elzinga BM, Spinhoven P, Everaerd WA. The effects of cortisol increase on long-term memory retrieval during and after acute psychosocial stress. Acta Psychologia (Amsterdam). 2008; 127:542-552.

Tollenaar MS, Elzinga BM, Spinhoven P, Everaerd W. Immediate and prolonged effects of cortisol, but not propranolol, on memory retrieval in healthy young men. Neurobiology of Learning and Memory. 2009; 91:23-31. [PubMed: 18761097]

Tolman, EC. Purposive behavior in animals and men. New York: The Century Co; 1932.

Tomaz C, Dickinson-Anson H, McGaugh JL. Basolateral amygdala lesions block diazepam-induced anterograde amnesia in an inhibitory avoidance task. Proceedings of the National Academy of Sciences of the United States of America. 1992; 89:3615-3619. [PubMed: 1565657]

Tully K, Bolshakov VY. Emotional enhancement of memory: how norepinephrine enables synaptic plasticity. Molecular Brain. 2010; 8:15-23. [PubMed: 20465834]

Van Stegeren AH. The role of the noradrenergic system in emotional memory. Acta Psychologia (Amsterdam). 2008; 127:532-541.

Van Stegeren AH. Imaging stress effects on memory: a review of neuroimaging studies. Canadian Journal of Psychiatry. 2009; 54:16-27.

Van Stegeren AH, Goekoop R, Everaerd W, Scheltens P, Barkhof F, Kuijer JP, Rombouts SA. Noradrenaline mediates amygdala activation in men and women during encoding of emotional material. NeuroImage. 2005; 24:898-909. [PubMed: 15652324]

Van Stegeren AH, Roozendaal B, Kindt M, Wolf OT, Joëls M. Interacting noradrenergic and corticosteroid systems shift human brain activation patterns during encoding. Neurobiology of Learning and Memory. 2010; 93:56-65. [PubMed: 19695335]

Vazdarjanova A, McGaugh JL. Basolateral amygdala is involved in modulating consolidation of memory for classical fear conditioning. Journal of Neuroscience. 1999; 19:6615-6622. [PubMed: 10414989] 
Vouimba RM, Richter-Levin G. Physiological dissociation in hippocampal subregions in response to amygdala stimulation. Cerebral Cortex. 2005; 15:1815-1821. [PubMed: 15716473]

Vouimba RM, Yaniv D, Richter-Levin G. Glucocorticoid receptors and beta-adrenoceptors in basolateral amygdala modulate synaptic plasticity in hippocampal dentate gyrus, but not in area CA1. Neuropharmacology. 2007; 52:244-252. [PubMed: 16890964]

Walker DL, Ressler KJ, Lu KT, Davis M. Facilitation of conditioned fear extinction by systemic administration or intra-amygdala infusions of D-cycloserine as assessed with fear-potentiated startle in rats. Journal of Neuroscience. 2002; 22:2343-2352. [PubMed: 11896173]

Wan RQ, Pang K, Olton DS. Hippocampal and amygdaloid involvement in nonspatial and spatial working memory in rats: effects of delay and interference. Behavioral Neuroscience. 1994; 108:866-882. [PubMed: 7826510]

Weil-Malherbe H, Axelrod J, Tomchick R. Blood-brain barrier for adrenalin. Science. 1959; 129:1226-1228. [PubMed: 13658949]

Weinberger NM. The nucleus basalis and memory codes: auditory cortical plasticity and the induction of specific, associative behavioral memory. Neurobiology of Learning and Memory. 2003; 80:268-284. [PubMed: 14521869]

Weinberger NM. Specific long-term memory traces in primary auditory cortex. Nature Reviews Neuroscience. 2004; 5:279-290.

Wilensky AE, Schafe GE, LeDoux JE. The amygdala modulates memory consolidation of fearmotivated inhibitory avoidance learning but not classical fear conditioning. Journal of Neuroscience. 2000; 20:7059-7066. [PubMed: 10995852]

Williams, CL.; Clayton, EC. Contribution of brainstem structures in modulating memory storage processes. In: Gold, PE.; Greenough, WT., editors. Memory consolidation: essays in honor of James L McGaugh. Washington, D.C: American Psychological Association; 2001. p. 141-163.

Williams, CL.; Jensen, RA. Vagal afferents: a possible mechanism for the modulation of peripherally acting agents. In: Frederickson, RCA.; McGaugh, JL.; Felten, DL., editors. Peripheral signaling of the brain: role in neural-immune interactions, learning and memory. New York: Hogrefe \& Huber; 1991. p. 467-472.

Williams CL, McGaugh JL. Reversible lesions of the nucleus of the solitary tract attenuate the memory-modulating effects of posttraining epinephrine. Behavioral Neuroscience. 1993; 107:18.

Williams CL, McGaugh JL. Enhancement of memory processing in an inhibitory avoidance and radial maze task by posttraining infusion of bombesin into the nucleus tractus solitarius. Brain Research. 1994; 654:251-256. [PubMed: 7987675]

Williams CL, Men D, Clayton EC. The effects of noradrenergic activation of the nucleus tractus solitarius on memory and in potentiating norepinephrine release in the amygdala. Behavioral Neuroscience. 2000; 114:1131-1144. [PubMed: 11142645]

Williams CL, Men D, Clayton EC, Gold PE. Norepinephrine release in the amygdala after systemic injections of epinephrine or inescapable footshock: contribution of the nucleus of the solitary tract. Behavioral Neuroscience. 1998; 112:1414-1422. [PubMed: 9926823]

Wolf OT, Convit A, McHugh PF, Kandil E, Thorn EL, De Santi S, McEwen BS, de Leon MJ. Cortisol differentially affects memory in young and elderly men. Behavioral Neuroscience. 2001; 115:1002-1011. [PubMed: 11584913]

Woodson JC, Macintosh D, Fleshner M, Diamond DM. Emotion-induced amnesia in rats: working memory-specific impairment, corticosterone-memory correlation, and fear versus arousal effects on memory. Learning \&Memory. 2003; 10:326-336. [PubMed: 14557605]

Wright CI, Beijer AVJ, Groenewegen HJ. Basal amygdaloid afferents to the rat nucleus accumbens are compartmentally organized. Journal of Neuroscience. 1996; 16:1877-1893. [PubMed: 8774456]

Yang Y, Cao J, Xiong W, Zhang J, Zhou QW, Wei H, Liang C, Deng J, Li T, Yang S, Xu L. Both stress experience and age determine the impairment or enhancement effect of stress on spatial memory retrieval. Journal of Endocrinology. 2003; 178:45-54. [PubMed: 12844335]

Yang YL, Chao PK, Lu KT. Systemic and intra-amygdala administration of glucocorticoid agonist and antagonist modulate extinction of conditioned fear. Neuropsychopharmacology. 2006; 31:912924. [PubMed: 16205786] 
Young AH, Sahakian BJ, Robbins TW, Cowen PJ. The effects of chronic administration of cortisone on cognitive function in normal male volunteers. Psychopharmacology (Berlin). 1999; 145:260 266. [PubMed: 10494574]

Zahrt J, Taylor JR, Mathew RG, Arnsten AF. Supranormal stimulation of D1 dopamine receptors in the rodent prefrontal cortex impairs spatial working memory performance. Journal of Neurosci. 1997; 17:8528-8535.

Zanatta MS, Schaeffer E, Schmitz PK, Medina JH, Quevedo J, Quillfeldt JA, Izquierdo I. Sequential involvement of NMDA receptor-dependent processes in hippocampus, amygdala, entorhinal cortex and parietal cortex in memory processing. Behavioral Pharmacology. 1996; 7:341-345.

Zorawski M, Killcross S. Posttraining glucocorticoid receptor agonist enhances memory in appetitive and aversive Pavlovian discrete-cue conditioning paradigms. Neurobiology of Learning and Memory. 2002; 78:458-464. [PubMed: 12431429] 

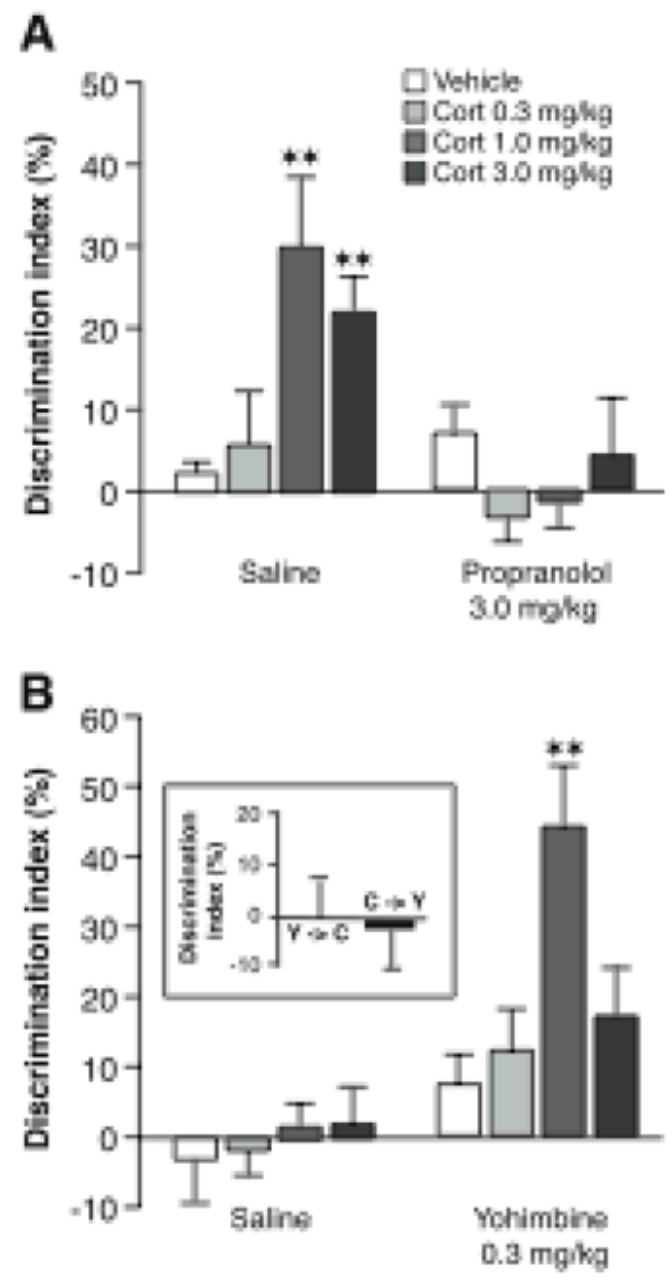

Figure 1.

Glucocorticoid effects on memory consolidation for object recognition training require noradrenergic activation. A, Immediate posttraining administration of the $\beta$-adrenoceptor antagonist propranolol $(3.0 \mathrm{mg} / \mathrm{kg}, \mathrm{sc})$ blocked the corticosterone-induced enhancement of object recognition memory in naïve rats. $\mathbf{B}$, The $\alpha_{2}$-adrenoceptor antagonist yohimbine $(0.3$ $\mathrm{mg} / \mathrm{kg}, \mathrm{sc}$ ) enabled corticosterone effect on object recognition memory in habituated rats. Inset, Posttraining injections of yohimbine $(0.3 \mathrm{mg} / \mathrm{kg}, \mathrm{sc})$ and corticosterone $(1.0 \mathrm{mg} / \mathrm{kg}$, sc) separated by a 4-hour delay did not induce memory enhancement. $\mathrm{Y} \rightarrow \mathrm{C}$; Yohimbine administered immediately after training and corticosterone 4 hours later; $\mathrm{C} \rightarrow \mathrm{Y}$; corticosterone administered immediately after training and yohimbine 4 hours later. Results represent discrimination index (mean \pm SEM) in percentage on a 24 -hour retention trial. The discrimination index was calculated as the difference in time spent exploring the two objects, expressed as the ratio of the total time spent exploring both objects. $\star \star, P<0.01$ as compared to the corresponding vehicle group. From Roozendaal et al., 2006a. 


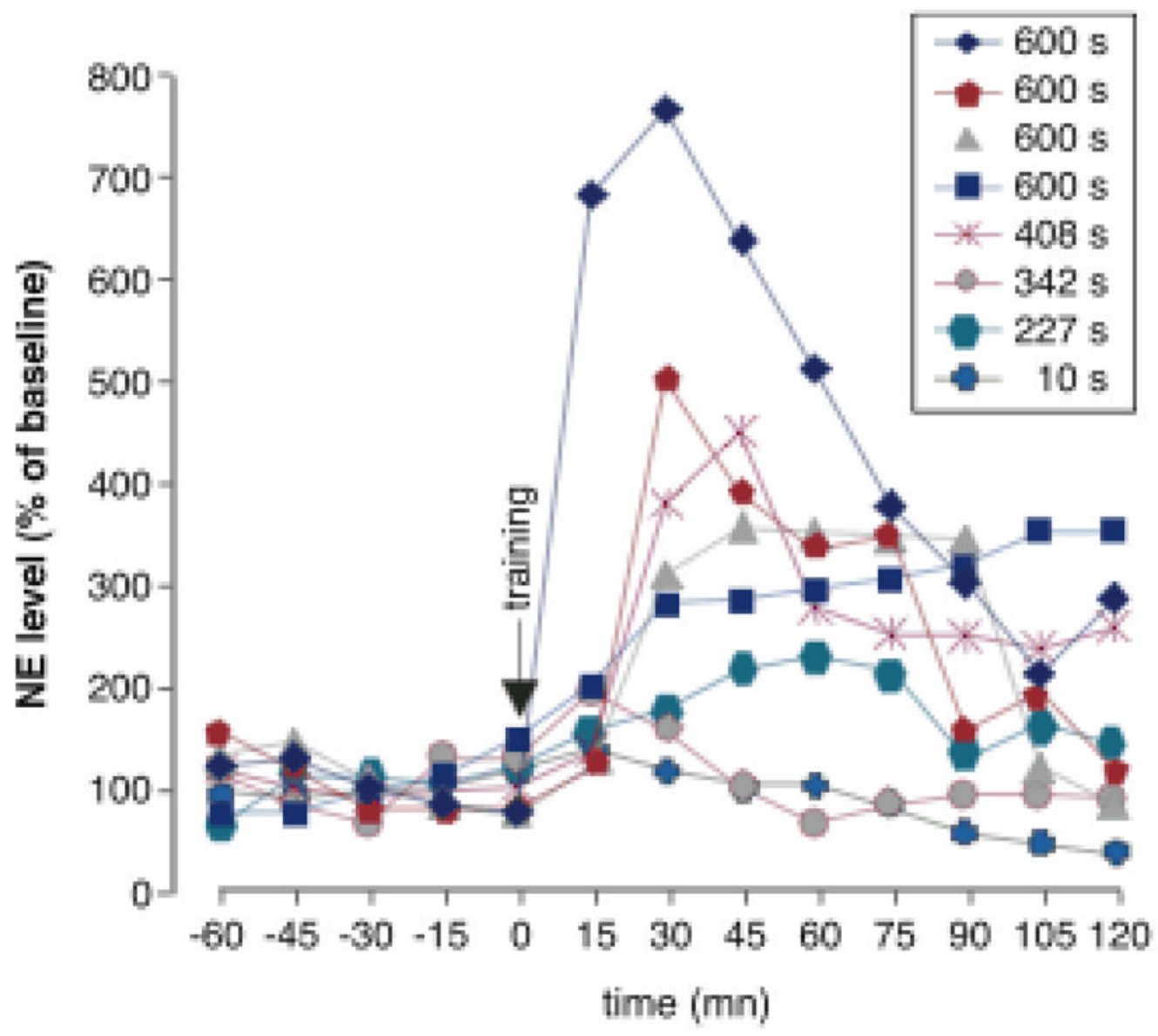

Figure 2.

Norepinephrine levels in the amygdala in individual animals following inhibitory avoidance training. Percent of baseline norepinephrine following inhibitory avoidance training is graphed for each individual rat. The key notes retention score on the following day. Amygdala norepinephrine levels correlate with 24-hour retention performance. Correlation values for the first five posttraining samples varied from +0.75 to +0.92 . From McIntyre et al., 2002. 

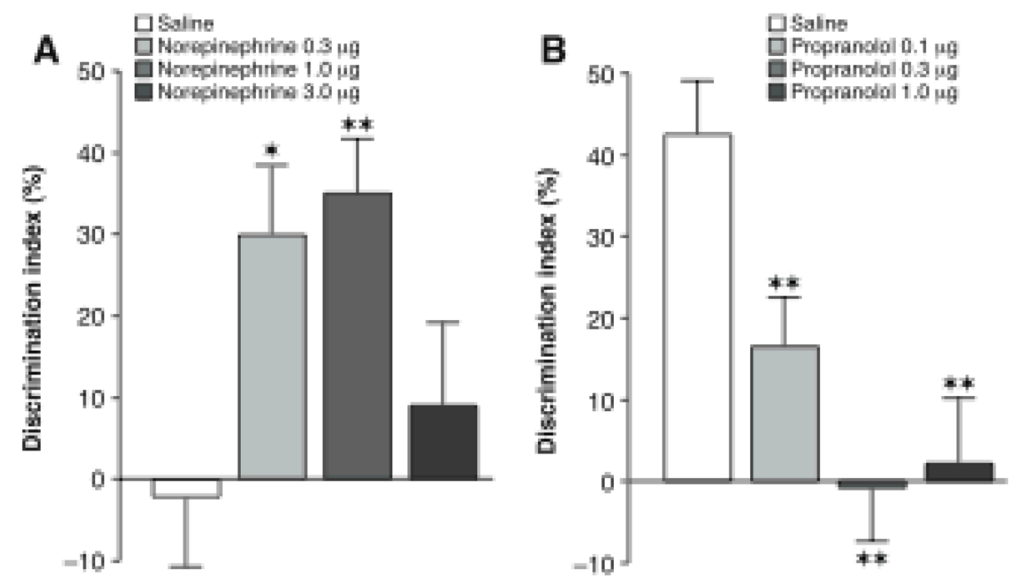

Figure 3.

Noradrenergic activation of the basolateral amygdala modulates consolidation of object recognition memory. A, Enhancing effects of posttraining intra-basolateral amygdala infusions of norepinephrine on 24-hour object recognition memory. Saline-infused controls displayed no evidence of memory of 3 minutes of training. The retention performance of groups given norepinephrine $(0.3$ or $1.0 \mu \mathrm{g}$ in $0.2 \mu \mathrm{l})$ after training was significantly better than that of saline controls. Data presented as discrimination index (mean $\pm \mathrm{SEM}$ ) in percentage on the 24-hour retention trial. The discrimination index was calculated as the difference in time spent exploring the two objects, expressed as the ratio of the total time spent exploring both objects. B, Impairing effects of posttraining intra-basolateral amygdala infusions of the $\beta$-adrenoceptor antagonist propranolol on 24-hour object recognition memory. All groups received 10 minutes of training. Saline-infused controls displayed significant memory and propranolol $(0.1,0.3$ or $1.0 \mu \mathrm{g}$ in $0.2 \mu \mathrm{l})$ produced dose-dependent impairment of memory. The performance of all three propranolol groups differed significantly from that of the corresponding saline controls. $\star, P<0.05 ; \star \star, P<0.01$ as compared to the corresponding saline controls. From Roozendaal et al., 2008b. 


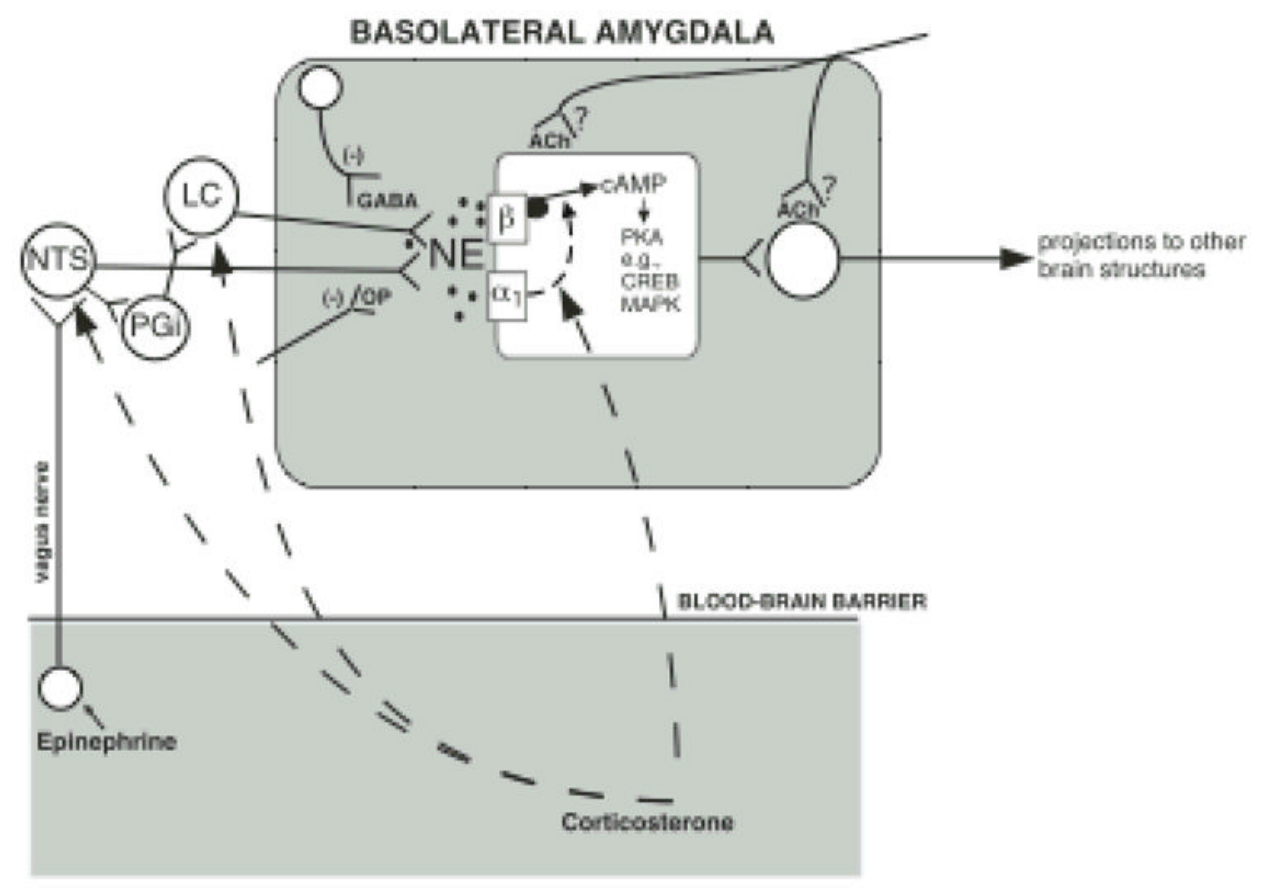

Figure 4.

Schematic summarizing the role of the noradrenergic system of the basolateral amygdala in memory consolidation. Norepinephrine (NE) is released in the basolateral amygdala following training in aversively motivated tasks and binds to both $\beta$-adrenoceptors and $\alpha_{1^{-}}$ adrenoceptors at postsynaptic sites. The $\beta$-adrenoceptor is coupled directly to adenylate cyclase to stimulate cAMP formation. The $\alpha_{1}$-adrenoceptor modulates the response induced by $\beta$-adrenoceptor stimulation. Intracellular cAMP can initiate a cascade of molecular events in the basolateral amygdala. The memory-modulatory effects of several other neuromodulatory influences, including that of epinephrine, glucocorticoid, opioid peptidergic and GABAergic systems, are mediated by converging influences on the noradrenergic system of the basolateral amygdala. Drug interactions with the noradrenergic system can occur at both presynaptic and postsynaptic loci. These noradrenergic effects in the basolateral amygdala are required for regulating memory consolidation in other brain regions. $\alpha_{1}, \alpha_{1}$-adrenoceptor; Ach, acetylcholine; $\beta, \beta$-adrenoceptor; cAMP, adenosine 3',5'cyclic monophosphate; CREB, cAMP-response element-binding protein; GABA, $\gamma$ aminobutyric acid; LC, locus coeruleus; MAPK, mitogen-activated protein kinase, NTS, nucleus of the solitary tract; OP, opioid peptide; Pgi, nucleus paragigantocellularis; PKA, protein kinase A. From McGaugh, 2000 and Roozendaal, 2000. 

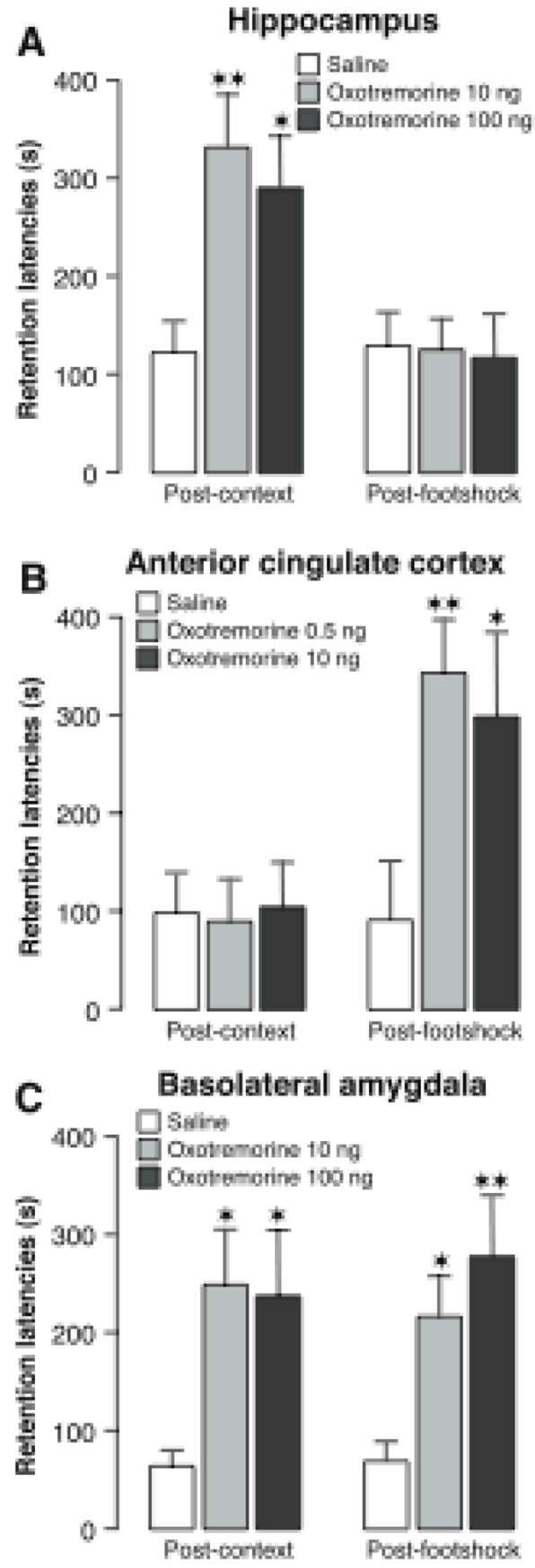

Figure 5.

Differential involvement of the hippocampus, anterior cingulate cortex and basolateral amygdala in memory for context and footshock. A, Posttraining infusions of the muscarinic cholinergic receptor agonist oxotremorine $(10$ or $100 \mathrm{ng}$ in $0.5 \mu \mathrm{l})$ into the dorsal hippocampus enhanced 48-hour inhibitory avoidance retention latencies when administered after context exposure but not after the shock exposure given 24 hours later. B, Posttraining infusions of oxotremorine $(0.5$ or $10 \mathrm{ng}$ in $0.5 \mu \mathrm{l})$ into the anterior cingulate cortex selectively enhanced 48-hour inhibitory avoidance retention latencies when administered after the shock experience but not after the context exposure. C, Posttraining infusions of oxotremorine (10 or $100 \mathrm{ng}$ in $0.2 \mu \mathrm{l}$ ) into the basolateral amygdala enhanced 48-hour 
inhibitory avoidance retention latencies when administered after either the context exposure or the shock experience. Results represent retention latencies (mean + SEM) in seconds. $\star$, $P<0.05 ; \star \star, P<0.01$ compared with the corresponding saline group. From Malin \& McGaugh, 2006. 


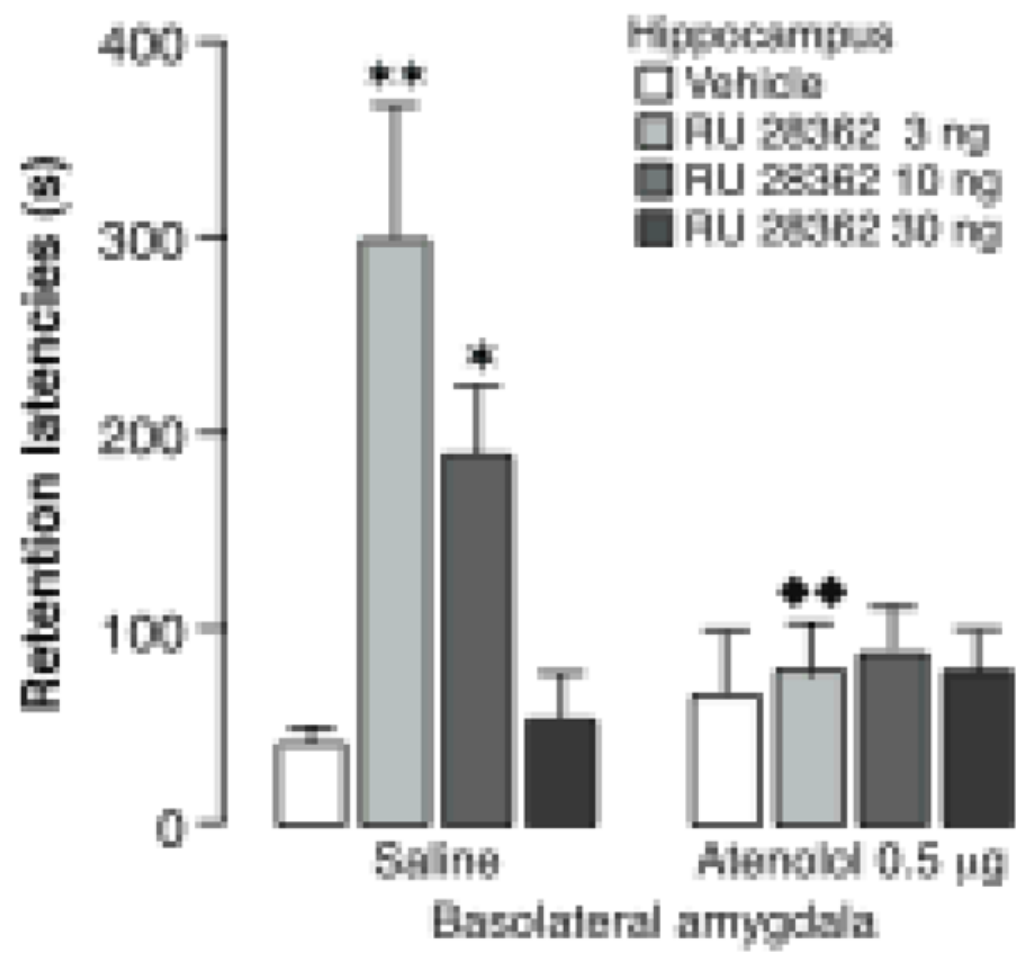

Figure 6.

Glucocorticoid effects in the hippocampus on memory consolidation require noradrenergic activity of the basolateral amygdala. Immediate posttraining unilateral infusions of the glucocorticoid receptor agonist RU 28362 (3, 10 or $30 \mathrm{ng}$ in $0.5 \mu \mathrm{l}$ ) into the hippocampus induced dose-dependent enhancement of 48-hour inhibitory avoidance retention latencies in rats given saline infusions into the basolateral amygdala concurrently. Ipsilateral infusions of the $\beta$-adrenoceptor antagonist atenolol $(0.5 \mu \mathrm{g}$ in $0.2 \mu \mathrm{l})$ into the basolateral amygdala blocked the memory enhancement induced by the glucocorticoid receptor agonist. Results represent retention latencies (mean $+\mathrm{SEM}$ ) in seconds. $\star, P<0.05 ; \star \star, P<0.01$ compared with the corresponding vehicle group. (1) 1 , $P<0.01$ compared with the corresponding saline group. From Roozendaal et al., 1999b. 

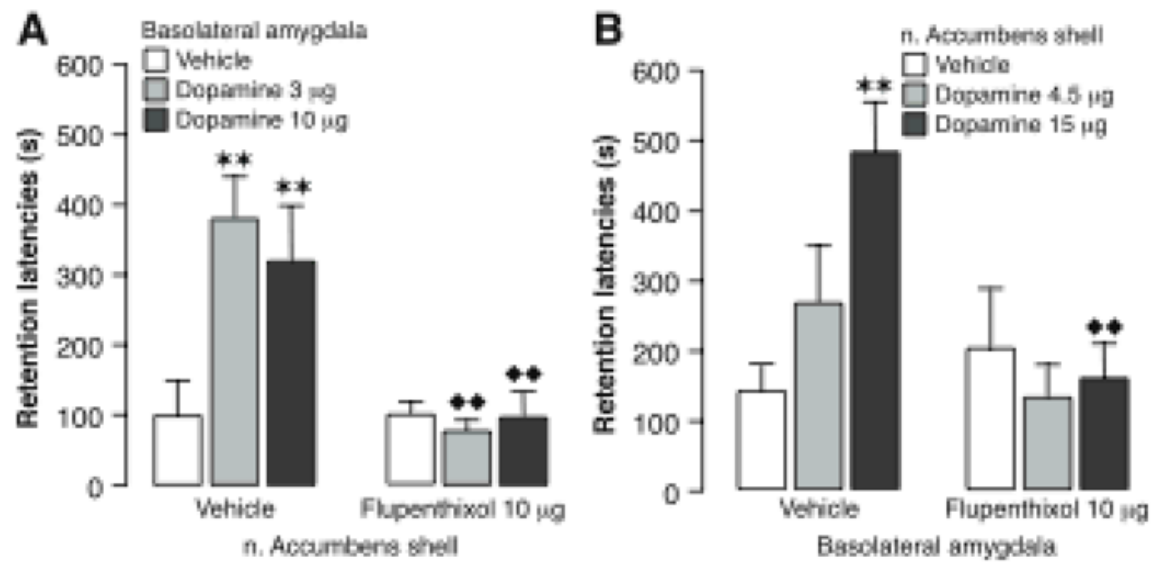

Figure 7.

Modulation of memory consolidation by the basolateral amygdala or nucleus accumbens shell requires concurrent dopamine receptor activation in both brain regions. A, Intrabasolateral amygdala infusions of dopamine ( 3 or $10 \mu \mathrm{g}$ in $0.2 \mu \mathrm{l}$ ) immediately after inhibitory avoidance training produced a dose-dependent enhancement of 48 -hour retention performance in rats receiving vehicle into the nucleus accumbens shell. Infusion of the nonselective dopamine receptor antagonist $c i$-flupenthixol $(10 \mu \mathrm{g}$ in $0.3 \mu \mathrm{l})$ into the nucleus accumbens shell blocked the memory enhancement induced by dopamine infusions into the basolateral amygdala. B, Intra-nucleus accumbens shell infusions of dopamine (4.5 or $15 \mu \mathrm{g}$ in $0.3 \mu \mathrm{l}$ ) also induced memory enhancement and this effect was blocked by concurrent infusions of cis-flupenthixol ( $10 \mu \mathrm{g}$ in $0.2 \mu \mathrm{l})$ into the basolateral amygdala. Results represent retention latencies (mean $+\mathrm{SEM}$ ) in seconds. $\star \star, P<0.01$ compared with the vehicle group; (1) (1) $P<0.01$ compared with the corresponding vehicle group. From LaLumiere et al., 2005. 


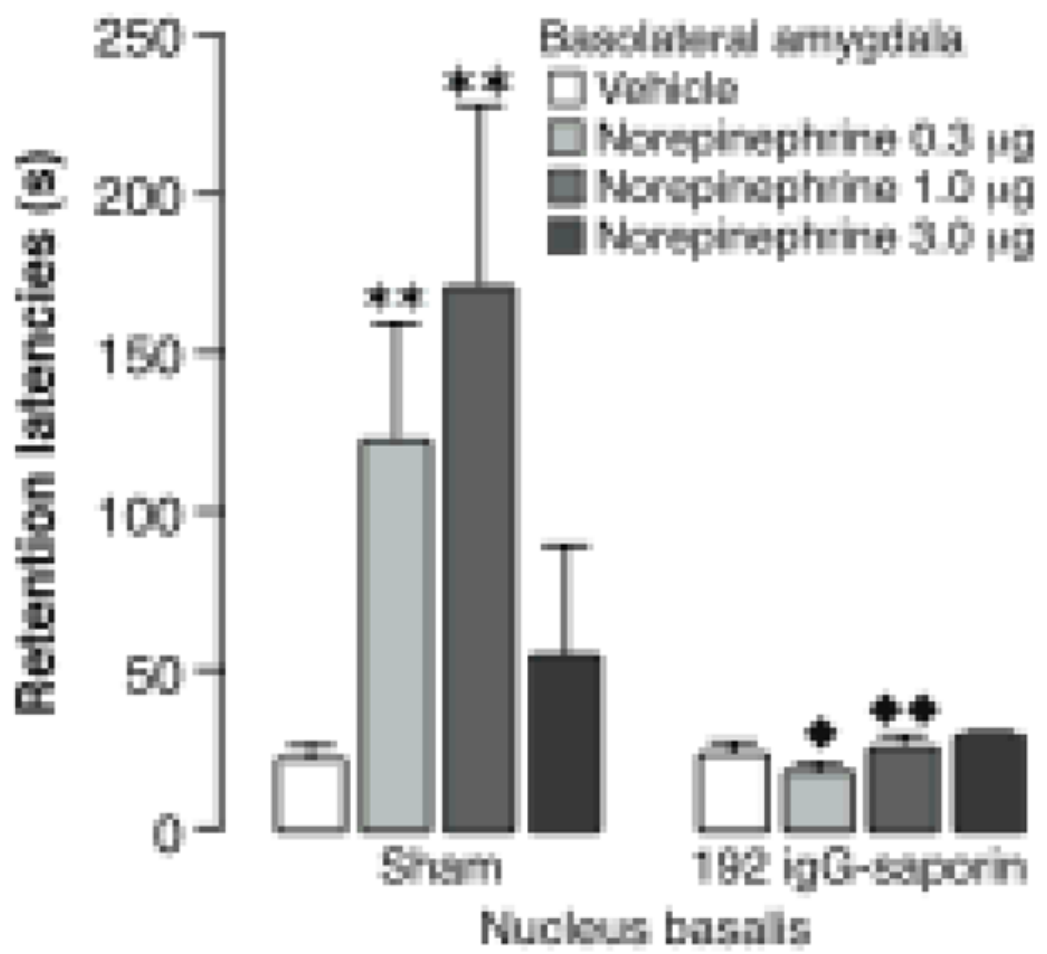

Figure 8.

Lesions of nucleus basalis cholinergic neurons with 192 IgG-saporin block the memory enhancement induced by posttraining infusions of norepinephrine into the basolateral amygdala. Intra-basolateral amygdala infusions of norepinephrine $(0.3,1.0$ or $3.0 \mathrm{ng}$ in 0.2 $\mu \mathrm{l})$ immediately after inhibitory avoidance training produced a dose-dependent enhancement of 48-hour retention performance in sham-operated rats. Rats with 192 IgG-saporin lesions did not show memory enhancement with norepinephrine infusions. Results represent retention latencies (mean $+\mathrm{SEM}$ ) in seconds. $\star, P<0.05 ; \star \star, P<0.01$ compared with the saline group; 1, $P<0.05$; 1 1,$P<0.01$ compared with the corresponding sham lesion group. From Power et al., 2002. 


\section{Initiation of Memory Consolidation}

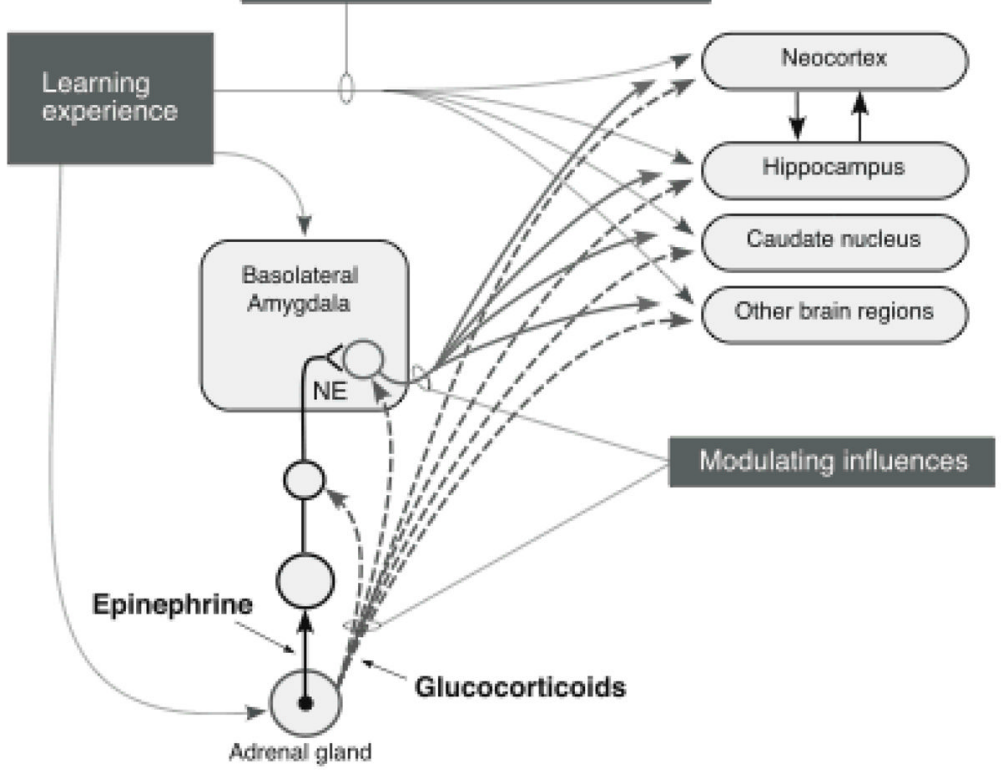

Figure 9.

Schematic summarizing interactions of the basolateral amygdala with other brain regions in mediating emotional arousal-induced modulation of memory consolidation. Experiences initiate memory consolidation in many brain regions involved in the forms of memory represented. Emotionally arousing experiences also release adrenal epinephrine and glucocorticoids and activate the release of norepinephrine in the basolateral amygdala. The basolateral amygdala modulates memory consolidation by influencing neuroplasticity in other brain regions. From McGaugh, 2000. 

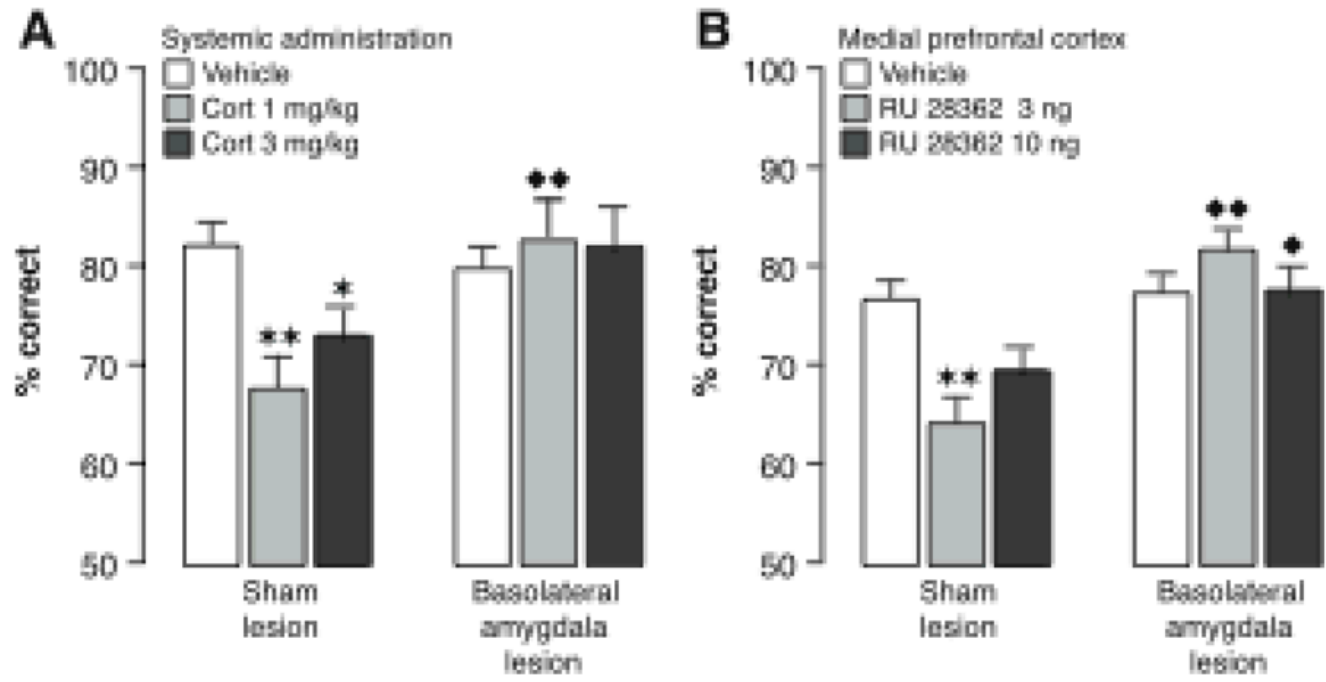

Figure 10.

The basolateral amygdala interacts with the medial prefrontal cortex in mediating glucocorticoid effects on working memory. Systemic injections of corticosterone (1.0 or 3.0 $\mathrm{mg} / \mathrm{kg}$, ip; A) or infusions of the specific glucocorticoid receptor agonist RU 28362 (3.0 or $10.0 \mathrm{ng}$ in $0.5 \mu \mathrm{l})$ into the medial prefrontal cortex $(\mathbf{B})$ impaired delayed alternation performance in sham-lesioned rats. Lesions of the basolateral amygdala blocked working memory impairment induced by either corticosterone or RU 28362. Results represent percent correct choices (mean $+\mathrm{SEM}) . \star \star, P<0.05 ; \star \star, P<0.01$ compared with the corresponding vehicle group; (1, $P<0.05$; (1) 1) $P<0.01$ compared with the corresponding sham-lesion group. From Roozendaal et al., 2004c. 
Table I

Treatment effects on memory and amygdala norepinephrine levels

\begin{tabular}{|l|l|l|l|}
\hline Treatment & Effect on memory & Effect on amygdala norepinephrine levels & Reference \\
\hline Footshock & Varies directly with footshock intensity & Varies with footshock intensity & Quirarte et al. 1998 \\
\hline Epinephrine & Enhances & Increases & Williams et al. 1998 \\
\hline Corticosterone & Enhances & Increases & McReynolds et al. 2010 \\
\hline Muscimol & Impairs & Decreases & Hatfield et al. 1999 \\
\hline Picrotoxin & Enhances & Increases & Hatfield et al. 1999 \\
\hline$\beta$-endorphin & Impairs & Decreases & Quirarte et al. 1998 \\
\hline Naloxone & Enhances & Increases & Quirarte et al. 1998 \\
\hline Orphanin FQ/nociceptin & Impairs & Decreases & Kawahara et al. 2004 \\
\hline
\end{tabular}

